DOE/RL-94-54

Revision 0

\title{
Pilot-Scale Treatability Test Plan for the 100-HR-3 Operable Unit
}

Date Published

August 1994

United States

Department of Energy

P.O. Box 550

Richland, Washingtori 99352 



\section{DISCLAIMER}

This report was prepared as an account of work sponsored by an agency of the United States Government. Neither the United States Government nor any agency thereof, nor any of their employees, make any warranty, express or implied, or assumes any legal liability or responsibility for the accuracy, completeness, or usefulness of any information, apparatus, product, or process disciosed, or represents that its use would not infringe privately owned rights. Reference herein to any specific commercial product, process, or service by trade name, trademark, manufacturer, or otherwise does not necessarily constitute or imply its endorsement, recommendation, or favoring by the United States Government or any agency thereof. The views and opinions of authors expressed herein do not necessarily state or reflect those of the United States Government or any agency thereof. 


\section{DISCLAIMER}

Portions of this document may be illegible in electronic image products. Images are produced from the best available original document. 


\section{EXECUTIVE SUMMARY}

This document presents the treatability test plan for pilot-scale pump-and-treat testing at the 100-HR-3 Operable Unit. The test will be conducted in fulfillment of interim Milestone M-15-06E to begin pilot-scale pump-and-treat operations by August 1994. The scope of the test was determined based on the results of lab/bench-scale tests (WHC 1993a) conducted in fulfillment of Milestone M-15-06B. These milestones were established per agreement between the U.S. Department of Energy (DOE), the Washington State Department of Ecology (Ecology) and the U.S. Environmental Protection Agency (EPA), and documented on Hanford Federal Facility Agreement and Consent Order Change Control Form M-15-93-02 (Ecology et al. 1994).

This test plan discusses a pilot-scale pump-and-treat test for the chromium plume associated with the D Reactor portion of the 100-HR-3 Operable Unit. Data will be collected during the pilot test to assess the effectiveness, operating parameters, and resource needs of the ion exchange (IX) pump-and-treat system. The test will provide information to assess the ability to remove contaminants by extracting groundwater from wells and treating extracted groundwater using IX.

Bench-scale tests were conducted previously in which chromium VI was identified as the primary contaminant of concern in the 100-D reactor plume. The DOWEX $21 \mathrm{~K}^{\mathrm{TM}}$ resin was recommended for pilot-scale testing of an IX pump-and-treat system. The bench-scale test demonstrated that the system could remove chromium VI from groundwater to concentrations less than $50 \mathrm{ppb}$. The test also identified process parameters to monitor during pilot-scale testing.

Water will be re-injected into the plume using weils outside the zone of influence and upgradient of the extraction well.

This test plan includes the following:

- A description of the pump-and-treat system

- $\quad$ Test performance objectives and data quality objectives (DQO)

- Discussion of the treatment technology and supporting field activities

- Discussion of monitoring activities

- Analytical requirements and quality assurance protocols

- $\quad$ Requirements for personnel and environmental health and safety and secondary waste handling and disposal

- Schedule and program organization.

Information obtained from the test will support Feasibility Studies for the 100-HR-3 Operable Unit in which effectiveness, operating requirements, and cost of the pump-and-treat alternative will be assessed. 


\section{ACRONYMS AND ABBREVIATIONS}

ARAR applicable or relevant and appropriate requirement

CERCLA Comprehensive Environmental Response, Compensation, and Liability Act

CFR

CV

Code of Federal Regulations

DOE

column volumes

DQO

U.S. Department of Energy

data quality objective

EII

EPA

HWOP

IRM

IX

Washington State Department of Ecology

Environmental Investigation Instruction

U.S. Environmental Protection Agency

Hazardous Waste Operations Plan

interim remedial measure

LFI ion exchange

M\&TE

MTCA

NPL

PARCC

PLC

QAPjP

SAP

limited field investigation

measuring and test equipment

Model Toxics Control Act

National Priorities List.

precision, accuracy, representativeness, completeness, and/or comparability programmable logic controller

quality assurance project plan

Tri-Party

sampling and analysis plan

Agreement

WAC

WCP

Hanford Federal Facility Agreement and Consent Order

Washington Administrative Code

waste control plan

WHC

Westinghouse Hanford Company 
DOE/RL-94-54, Rev. 0 


\section{CONTENTS}

1.0 INTRODUCTION $\ldots \ldots \ldots \ldots \ldots \ldots \ldots \ldots \ldots \ldots \ldots \ldots \ldots \ldots \ldots \ldots$

1.1 IRM PROPOSED PLAN $\ldots \ldots \ldots \ldots \ldots \ldots \ldots \ldots \ldots \ldots \ldots \ldots \ldots$

1.2 SITE DESCRIPTION AND CONTAMINANTS $\ldots \ldots \ldots \ldots \ldots \ldots \ldots$

1.3 GROUNDWATER CONCEPTUAL MODEL $\ldots \ldots \ldots \ldots \ldots \ldots \ldots$

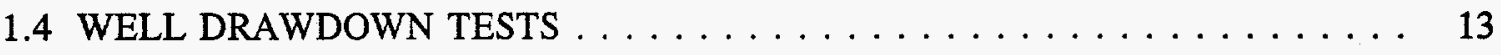

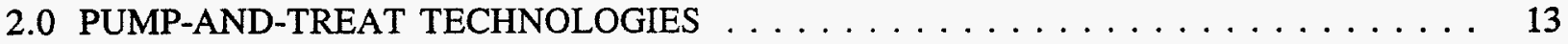

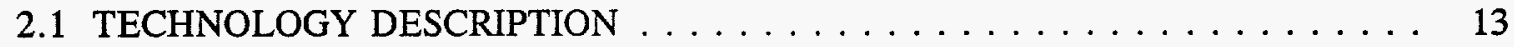

2.2. LABORATORY TESTS $\ldots \ldots \ldots \ldots \ldots \ldots \ldots \ldots \ldots \ldots \ldots$

3.0 TREATABILITY TEST PERFORMANCE AND DATA QUALITY OBJECTIVES $\ldots \ldots$

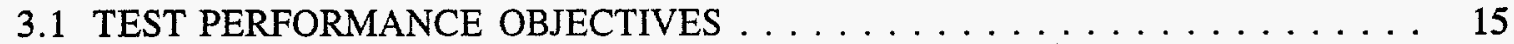

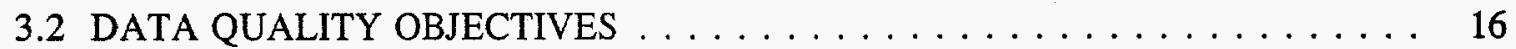

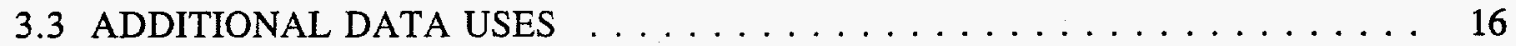

3.4 APPLICABLE RELEVANT AND APPROPRIATE REQUIREMENTS . . . . . . 21

4.0 TREATABILITY TEST DESIGN AND OPERATING REQUIREMENTS $\ldots \ldots \ldots \ldots$

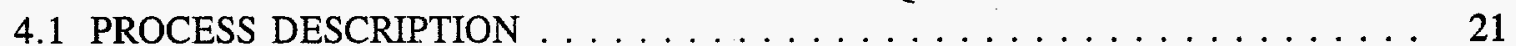

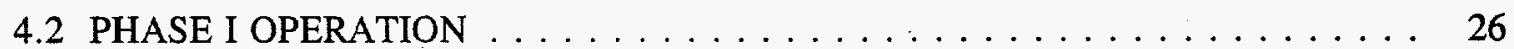

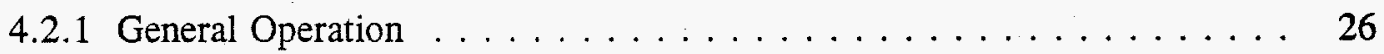

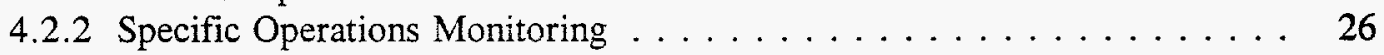

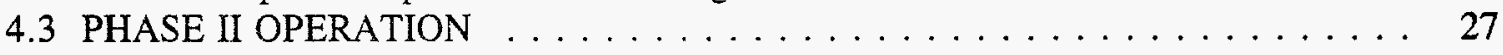

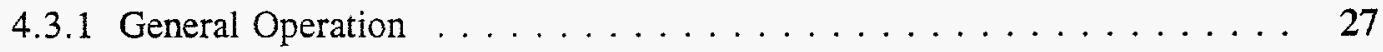

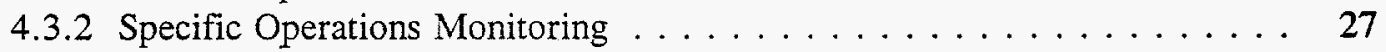

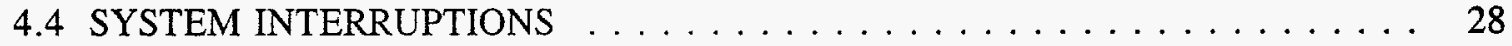

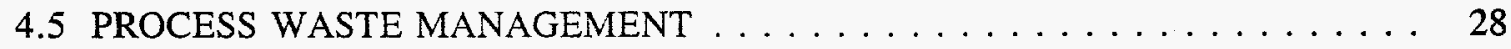

4.6 PILOT-SCALE TREATABILITY TEST SAMPLING AND MONITORING . . . . . 28

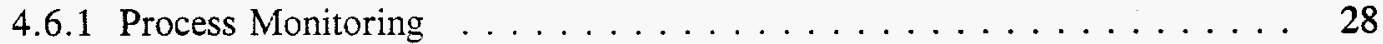

4.6 .2 Groundwater Monitoring . . . . . . . . . . . . . . . . 29

5.0 REQUIREMENTS . . . . . . . . . . . . . . . . . . . . . . . . . . . . 29

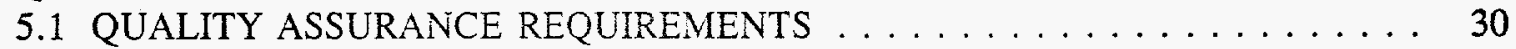

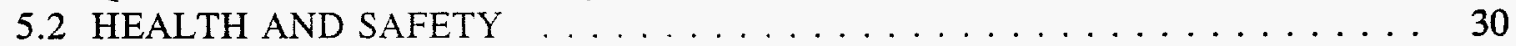

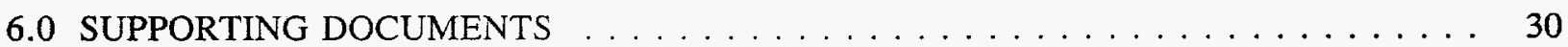

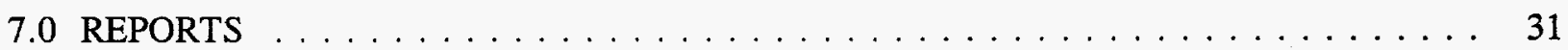

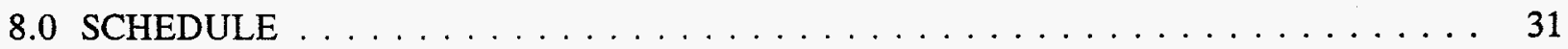

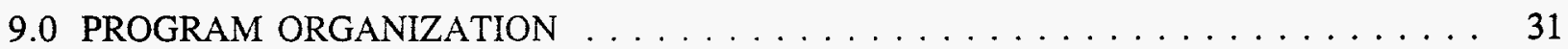

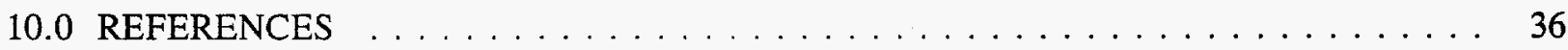


DOE/RL-94-54, Rev. 0

CONTENTS (Cont.)

\section{APPENDICES:}

A 100-HR-3 Operable Unit Treatability Test Process Sampling and Analysis Plan

B 100-HR-3 Operable Unit Treatability Test Quality Assurance Project Plan

C Equipment Specifications

\section{FIGURES:}

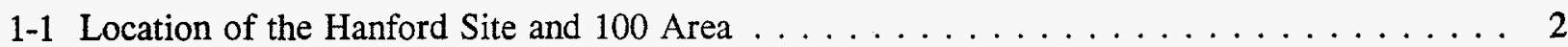

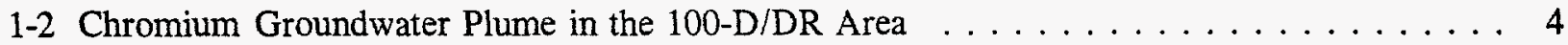

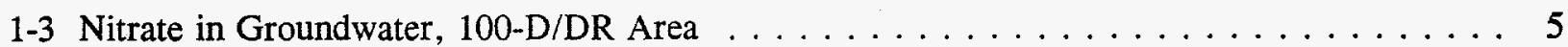

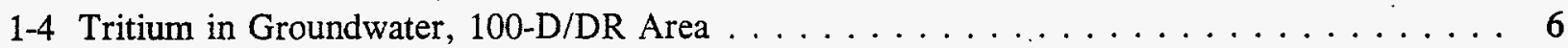

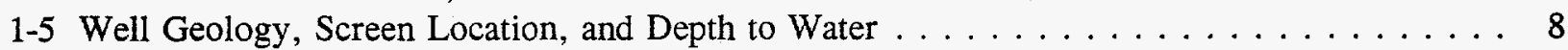

1-6 Groundwater Elevations in the $100-\mathrm{D} / \mathrm{DR}$ Area . . . . . . . . . . . . . . . 9

4-1 Layout for the Extraction, Ion Exchange, and Injection System . . . . . . . . . . . 22

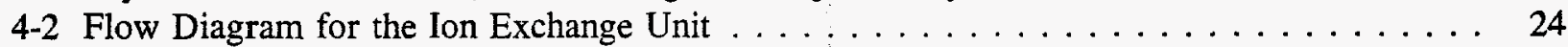

8-1 100-HR-3 Operable Unit Treatability Test Schedule $\ldots \ldots \ldots \ldots \ldots \ldots \ldots$

9-1 100-HR-3 Operable Unit Treatability Test Program Organization . . . . . . . . . . . . . 34

\section{TABLES:}

1-1 Summary Production Information for Potential 100-D Area Pump-and-Treat Pilot Test

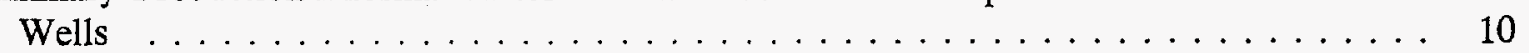

1-2 Chemical Analysis of Samples from Extraction and Injection Wells . . . . . . . . . . 11

3-1 Data Quality Objectives . . . . . . . . . . . . . . . . . . . . . 17

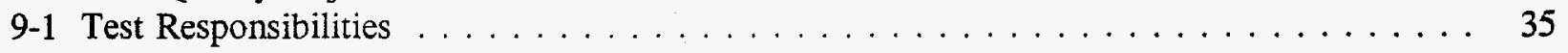




\subsection{INTRODUCTION}

The 100 Area of the Hanford Site (Figure 1-1) is included on the U.S. Environmental Protection Agency (EPA) National Priorities List (NPL) under the Comprehensive Environmental Response, Compensation, and Liability Act (CERCLA). The Hanford Site, established in 1943, was originally designed, built, and operated to produce plutonium for nuclear weapons using production reactors and chemical reprocessing plants. The 100 Areas were the site of nine reactor facilities. Cooling effluent from the reactors was discharged to the Columbia River via retention basins, cribs, trenches, and french drains. Reactor hardware and other solid waste was disposed of in burial grounds in the 100 Areas. As a result of these operations, soils and groundwater were contaminated.

An ongoing groundwater monitoring program is in place to monitor contaminant levels and migration of plumes in the 100 Areas. Facility operations and the historical monitoring program are included in the Investigation/Corrective Measures Study Work Plan for the 100-HR-3 Operable Unit (DOE-RL 1992a). New data are contained in the 100-HR-3 Limited Field Investigations (LFI) Report (DOE-RL 1993).

Phase I and II Feasibility Studies conducted for the 100 Area (DOE-RL 1992b) screened technologies for groundwater remediation in the 100 Area and provided a preliminary assessment of alternatives. The alternatives include no action, institutional control, pump and treat, treatment at point of use/discharge, and physical or hydraulic containment/control. Pump and treat has been agreed upon by the U.S. Department of Energy (DOE), EPA, and the Washington State Department of Ecology (Ecology) for pilot-scale testing in the 100-HR-3 Operable Unit as documented in Federal Agreement and Consent Order Change Control Form M-15-93-02 (Ecology et al. 1994).

This test plan describes a pump-and-treat treatability test to be conducted in the 100-HR-3 Operable Unit. The test plan describes the purpose, scope, objectives, and location of the treatability test; discusses the treatment technologies chosen for testing and the treatability test system design, operation and monitoring; and includes a test schedule. The test plan is a secondary document, as defined in the Hanford Federal Facility Agreement and Consent Order (Tri-Party Agreement; Ecology et al. 1989a).

The test will establish the effectiveness of pump-and-treat systems in the 100-HR-3 Operable Unit (specifically the D Reactor area) and the operating parameters and resource needs associated with extracting and treating groundwater. The test will establish engineering design values and functional costs to support the evaluation of pump-and-treat iechnologies as a remedial alternative.

Rationale for the test include:

- $\quad$ Current evidence (see Section 1.3) indicates that chromium VI is mobile within the D Reactor chromium VI plume, so it is expected it will be removed in the pump-andtreat process.

- Although pump and treat is generally considered a viable means of reducing the mass of mobile contaminants in groundwater, numerous site-specific factors influence the effectiveness and selection of pump and treat. Data on treatment effectiveness in the D Reactor area are needed. 
Figure 1-1. Location of the Hanford Site and 100 Area.

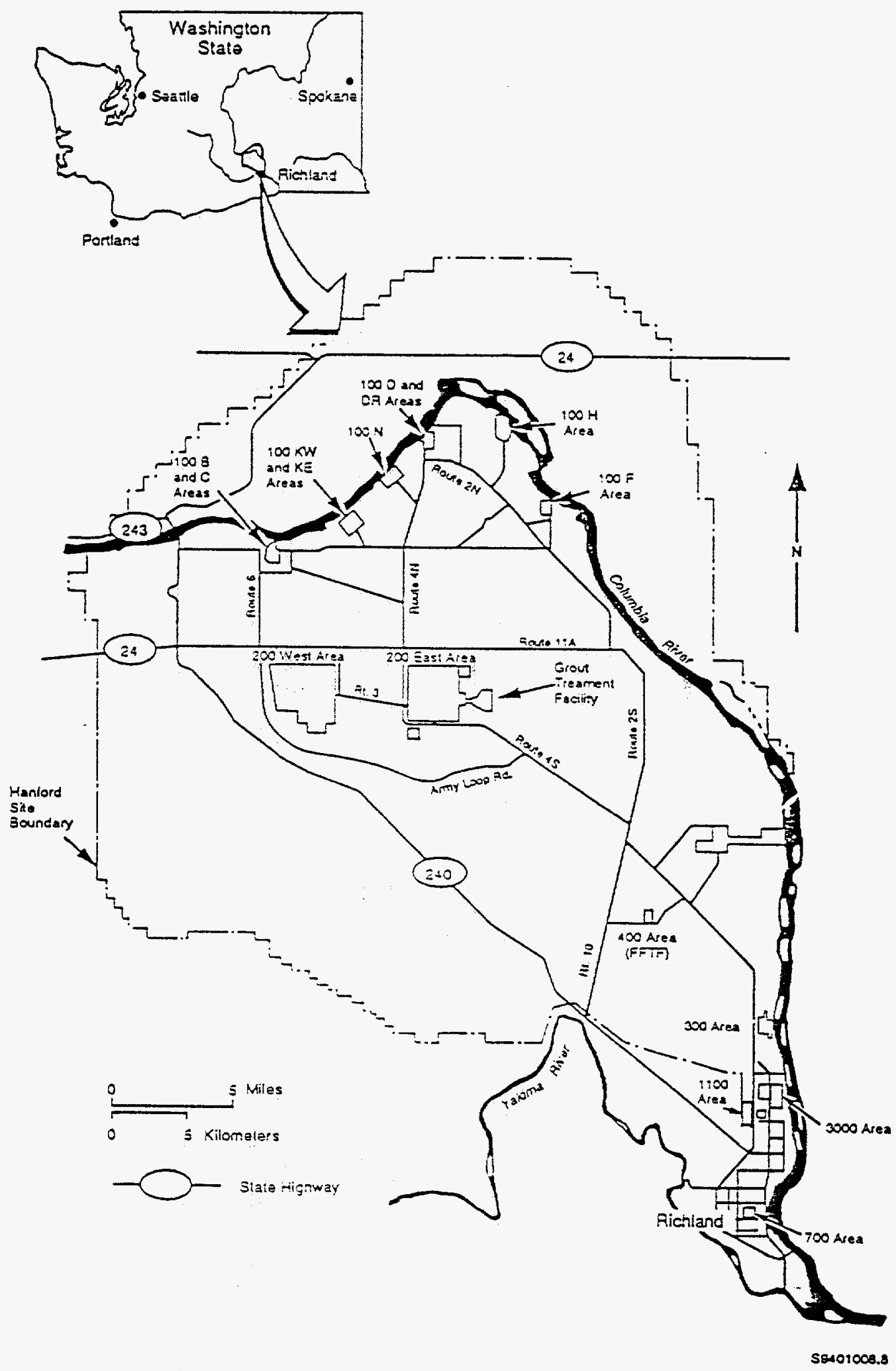


- Treatment system test results will provide data for chromium VI remediation that may be useful to other 100 Area locations.

The test will consist of two phases.

In Phase I, groundwater will be extracted from a three-well network (D5-15, D5-14, and D5-16), treated in an ion exchange (IX) unit, and reinjected into one or more upgradient wells (D5-17, D5-18, and D5-19). The pump-and-treat system will operate nominally $8 \mathrm{~h} /$ day, 5 days/week. This test will demonstrate the effectiveness of IX in treating effluent in the field as compared with laboratory test results. Phase I operations and winterization of the treatment system are scheduled for completion prior to November 15, 1994.

In Phase II, the treatment system will operate continuously $24 \mathrm{~h} /$ day, 7 days/week. Effluent will be reinjected as in Phase I. Over time, chromium VI levels in the groundwater plume will be monitored and the mass reduction of chromium in the plume will be determined.

Monthly updates on Phase I and Phase II test results will be provided in Unit Manager Meeting status packages. Project status information may also be shared upon regulator request.

\subsection{IRM PROPOSED PLAN}

An Interim Remedial Measure (IRM) Proposed Plan for the 100-HR-3 Operable Unit is being developed. The IRM Proposed Plan will describe this test program and any additional field characterization activities necessary to support an IRM. It will also address CERCLA requirements, including applicable or relevant and appropriate federal and state requirements (ARAR) pertinent to the interim actions.

It is anticipated that the IRM will be a continuation of Phase II testing, with the potential to increase the number of wells being pumped and to drill additional extraction and injection wells if needed. Implementation of the IRM is contingent on results of the test.

\subsection{SITE DESCRIPTION AND CONTAMINANTS}

The qualitative risk assessment conducted from data gathered for the 100-HR-3 LFI identified chromium, nitrate, tritium, ${ }^{1+} \mathrm{Co}$, and ${ }^{90} \mathrm{Sr}$ as constituents to be carried on in the LFI process. Of these constituents, ${ }^{14} \mathrm{Co}$ was reported only in samples from D5-12 and ${ }^{90} \mathrm{Sr}$ occurred in concentrations above drinking water standards only in samples from D5-12. Figures 1-2, 1-3, and 1-4 are plume maps of chromium, nitrate, and tritium, respectively. It is expected that much of the chromium in the plume shown in Figure 1-2 is chromium VI (hexavalent chromium). In this document, except where indicated otherwise, discussion of chromium or figures of chromium plumes refer to total chromium, or a combination of chromium III and chromium VI.

The highest concentrations of chromium (2090 ppb unfiltered, $2020 \mathrm{ppb}$ filtered) were detected north of the D Reactor Building in well 199-D5-15 in May 1992. Filtered water samples collected in March 1993 were characterized by up to $1570 \mathrm{ppb}$ chromium (see Figure 1-2). The unfiltered chromium concentration from the same samples was characterized by up to $1630 \mathrm{ppb}$. 


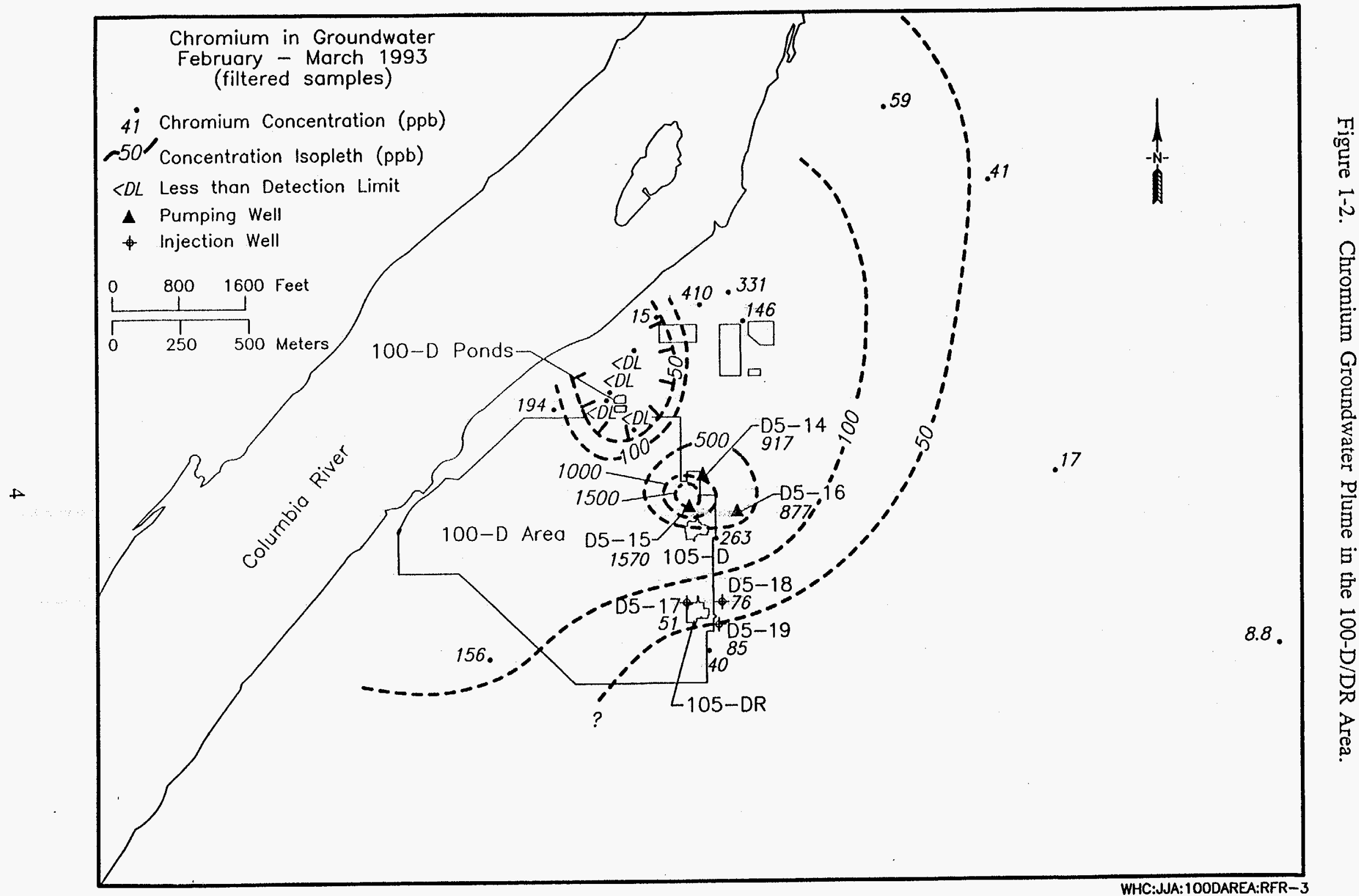


Figure 1-3. Nitrate in Groundwater, 100-D/DR Area.

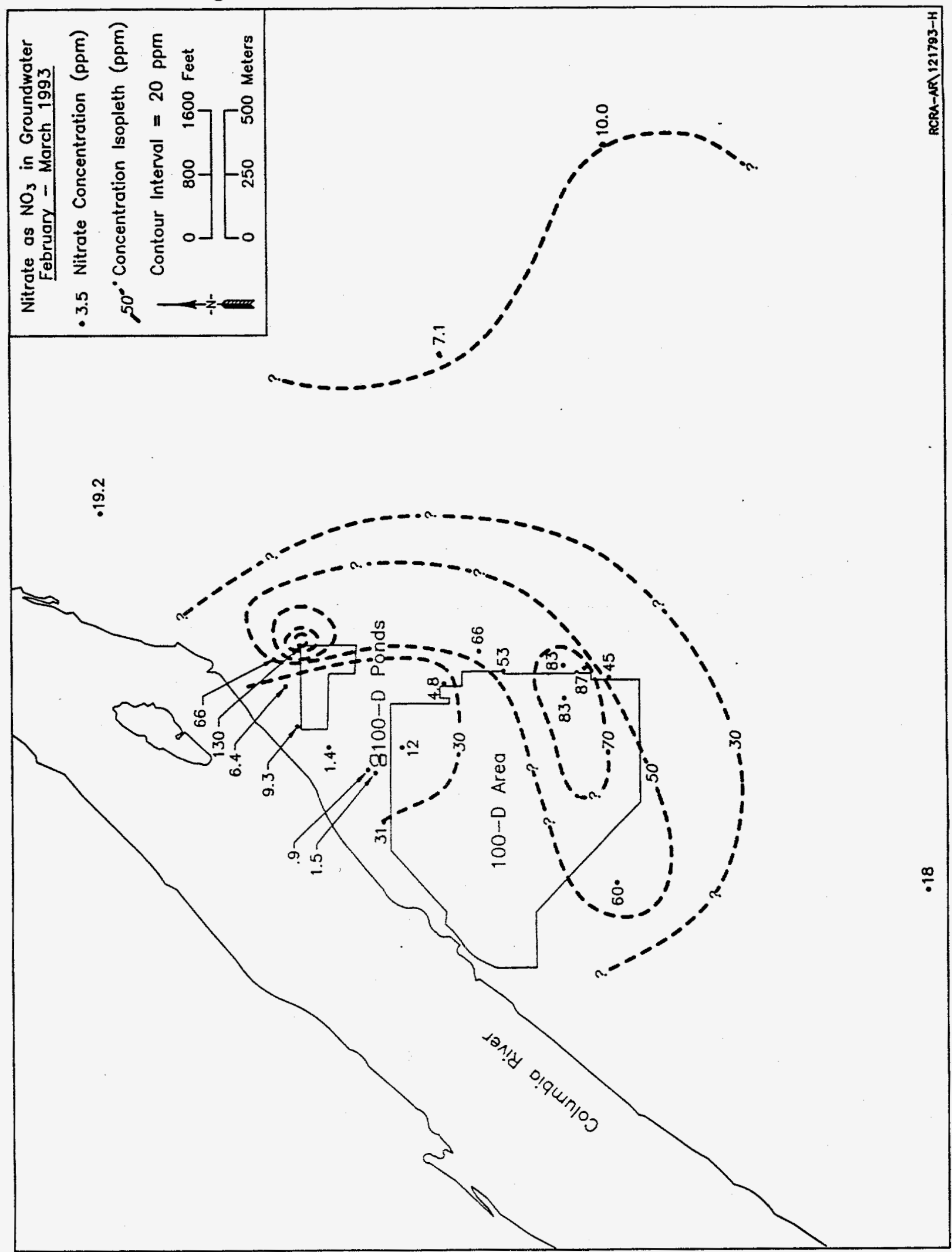




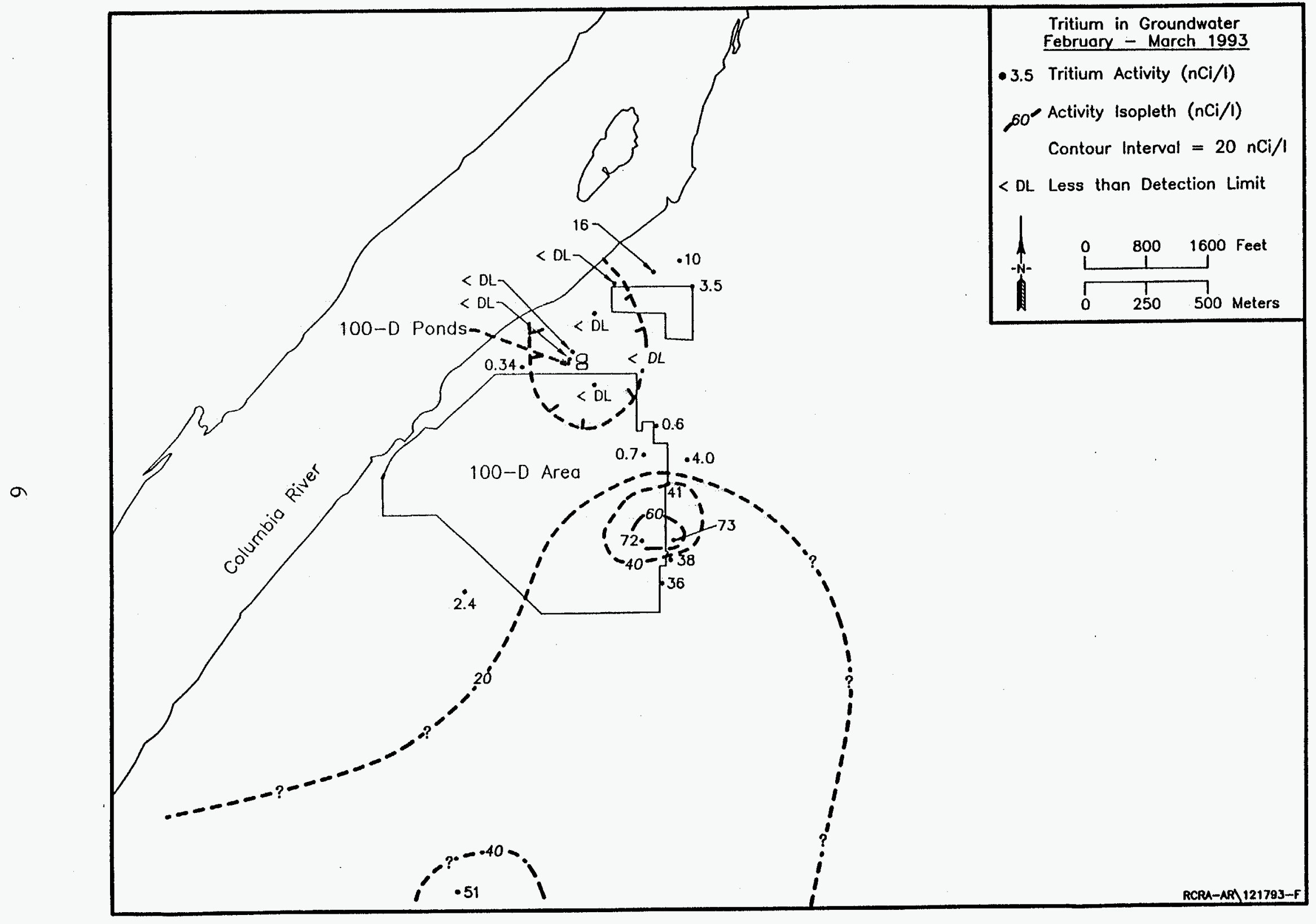


To meet the cleanup requirements associated with Milestone M-15-06E, the 100-D/DR Area was chosen for a pilot-scale pump-and-treat operation because the chromium concentrations are an order of magnitude greater at the 100-D Area than at the 100-H Area. The relatively narrow configuration of the chromium plume in proximity to well D5-15 (highest chromium concentrations) was also a consideration.

The test will be conducted in the area east of the 100-D and 100-DR Reactors. The Hanford/Ringold contact east of the D/DR Reactors is characterized by Hanford gravel overlying Ringold gravel (Figure 1-5). Monitoring wells 199-D5-14, 15, 16, and 19 are screened entirely in the Ringold Formation. Monitoring well 199-D5-17 is screened in the Hanford formation, and well 199-D5-18 is screened in both the Hanford and Ringold Formations. Wells screened in the Ringold Formation can generally be expected to produce less water than comparable wells screened in the Hanford Formation (Table 1-1). However, the well tests at this location indicate that the Ringold/Hanford completion at D5-18 has a higher conductivity than the Hanford completion in D5-17. Groundwater flow is to the north and northwest with a gradient of 4E-4 (Figure 1-6). Riverstage elevations at $100-\mathrm{H}$, approximately $5 \mathrm{mi}$ downstream of $100 \mathrm{D} / \mathrm{DR}$, varied from $372.3 \mathrm{ft}$ to $376.8 \mathrm{ft}$ abọve mean sea level on December 20, 1993.

Monitoring Wells D5-14, D5-15, and D5-16 were selected as the extraction well network because they are located in close proximity and within the highest concentrations of the chromium plume (see Figure 1-2). Wells D5-17, D5-18, and D5-19 were selected as injection wells because they are the nearest wells to the extraction well network, they are upgradient of the extraction wells, and the estimated well capacities exceed the extraction well capacities. (Due to the apparent marginal capacity of D5-17, it has been included as a potential option that may be exercised in the future.) The injection wells are located in a source area for co-contaminants (see Figure 1-4).

Co-contaminants, if any, may be returned to the immediate upgradient plume via the injection wells. Table 1-2 presents recent chemical analyses of samples collected from both the extraction and injection wells.

\subsection{GROUNDWATER CONCEPTUAL MODEL}

The groundwater conceptual model for the 100D/DR Area includes information about contaminant sources, disposal practices, and aquifer characteristics. The conceptual model was developed from data and information contained in RCRA Facility Investigation/Corrective Measures Study Work Plan for the 100-DR-1 Operable Unit, Hanford Site, Richland, Washington (DOE/RL 1990) and from the Limited Field Investigation Report for the 100-HR-3 Operable Unit (DOE/RL 1.993).

The probable source of the chromium in the groundwater is the $3740 \mathrm{lb}$ of sodium dichromate that was buried in the 116-D-1A and 116-D-1B Fuel Storage Basin Trenches. These trenches are located to the southeast of the D Reactor. Additionally, unknown volumes of contaminated water from the D Reactor basin (118-D-6) were pumped into the fuel storage basin trenches from 1947 to 1967. Finally, approximately $110,000 \mathrm{lb}$ of sludge was pumped from the $118-\mathrm{D}-6$ Basin to the fuel storage basin trenches during the 1950s. Formational porosity in the Ringold and Hanford formations is estimated at $10 \%$ and $20 \%$, respectively. Flow velocity in the Ringold Formation is estimated at $0.2 \mathrm{ft} / \mathrm{day}$. 
DOE/RL-94-54, Rev. 0

Figure 1-5. Well Geology, Screen Location, and Depth to Water.
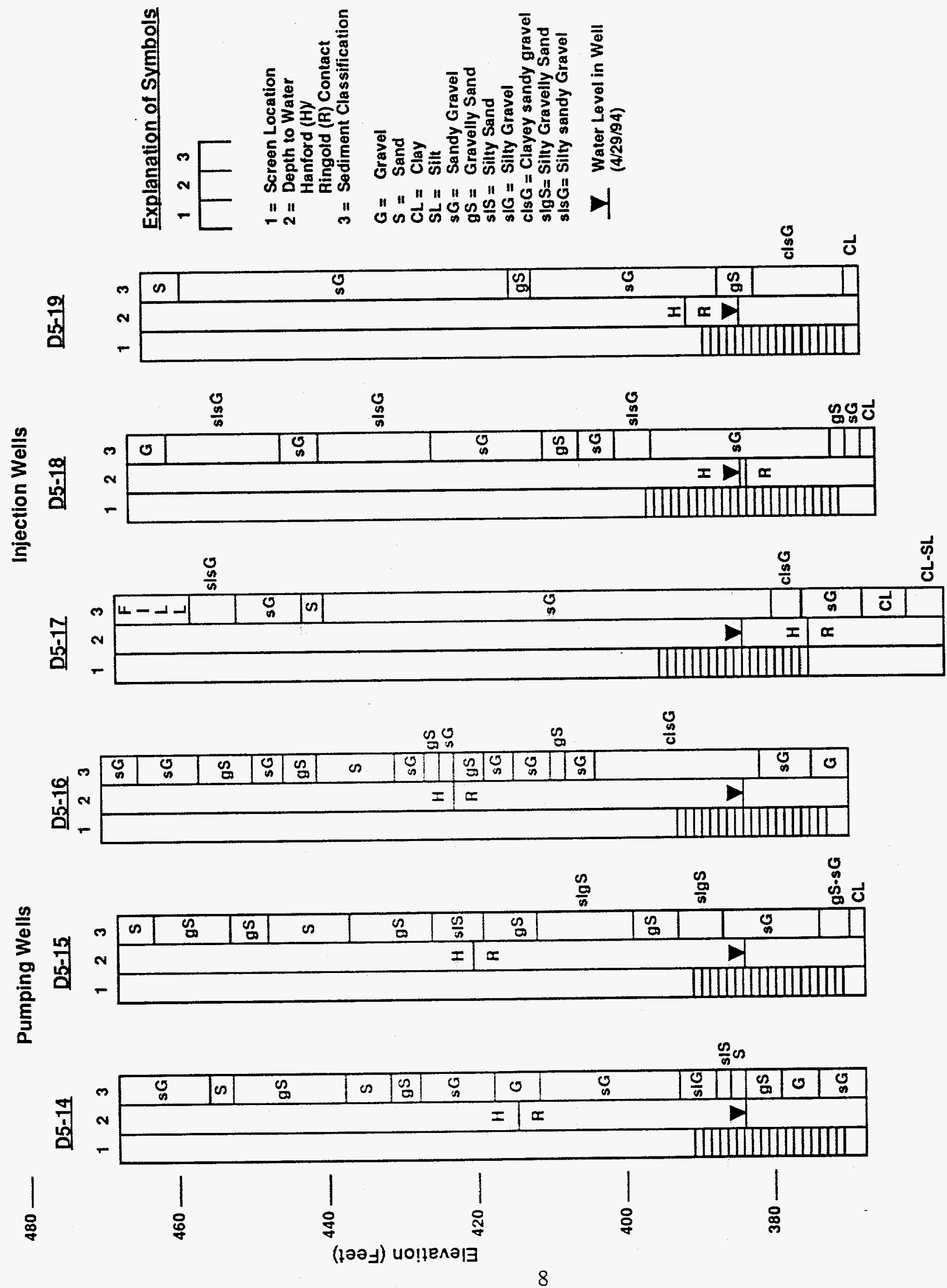


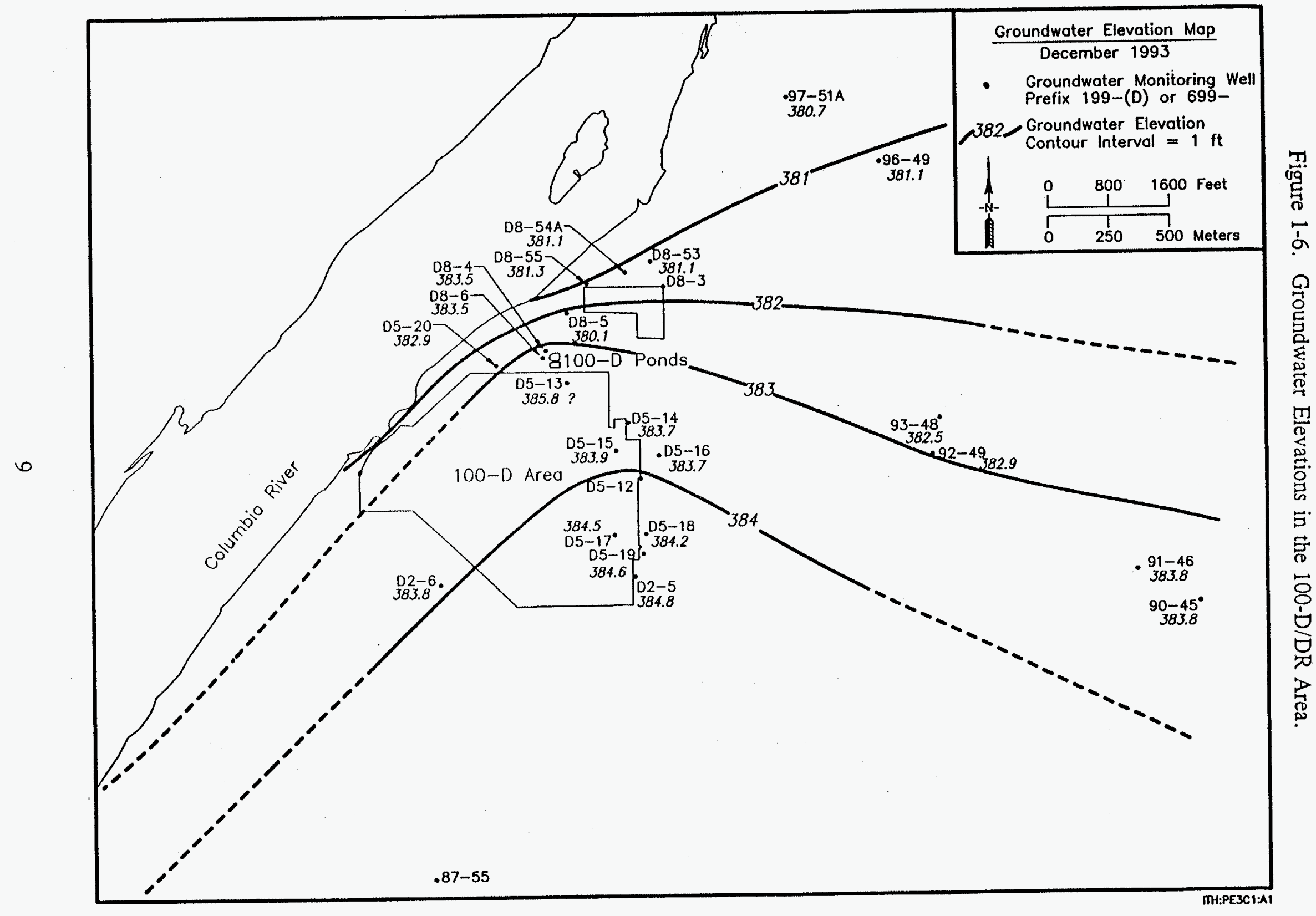


Table 1-1. Summary Production Information for Potential 100-D Area Pump-and-Treat Pilot Test Wells.

\begin{tabular}{|c|c|c|c|c|c|c|}
\hline wernanes & 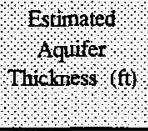 & Subnerged & Estimated $\mathrm{K}$ & $\begin{array}{l}\text { Specific } \\
\text { Capacity } \\
\text { galrinift) }\end{array}$ & 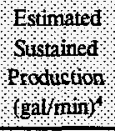 & Comment \\
\hline 199-D5-14 & 19 & 14.6 & 49 & 0.95 & $3-5$ & \\
\hline 199-D5-15 & 19 & 15.0 & 54 & 3.7 & $14-19$ & Best Pumping Well \\
\hline 199-D5-16 & 18 & 12.7 & 13 & 0.45 & $1-2$ & \\
\hline 199-D5-17 & 22 & 15.9 & 16 & 0.36 & $1-2$ & \\
\hline 199-D5-18 & 20 & 15.4 & 84 & 5.3 & $20-28$ & Best Injection Well \\
\hline 199-D5-19 & 18 & 18 & 56 & 1.7 & $15-18$ & \\
\hline
\end{tabular}

1. Top three wells are potential extraction wells; Last three wells are potential injection wells.

2. $\mathrm{K}=$ hydraulic conductivity

3. Specific capacity was determined from well development data, where water was discharged for a period $<48 \mathrm{~min}$ for wells 14 to 16 , and $<115 \mathrm{~min}$ for wells $17-19$.

4. Sustained production/injection is based on $50 \%$ to $70 \%$ of the specific capacity at a maximum drawdown of $1 / 2$ the length of the submerged screen. One-half of the submerged screen is recommended to reduce cavitation and to keep the pump cooled. An additional subjective production factor was added to well D5-19 because of the greater available drawdown. 


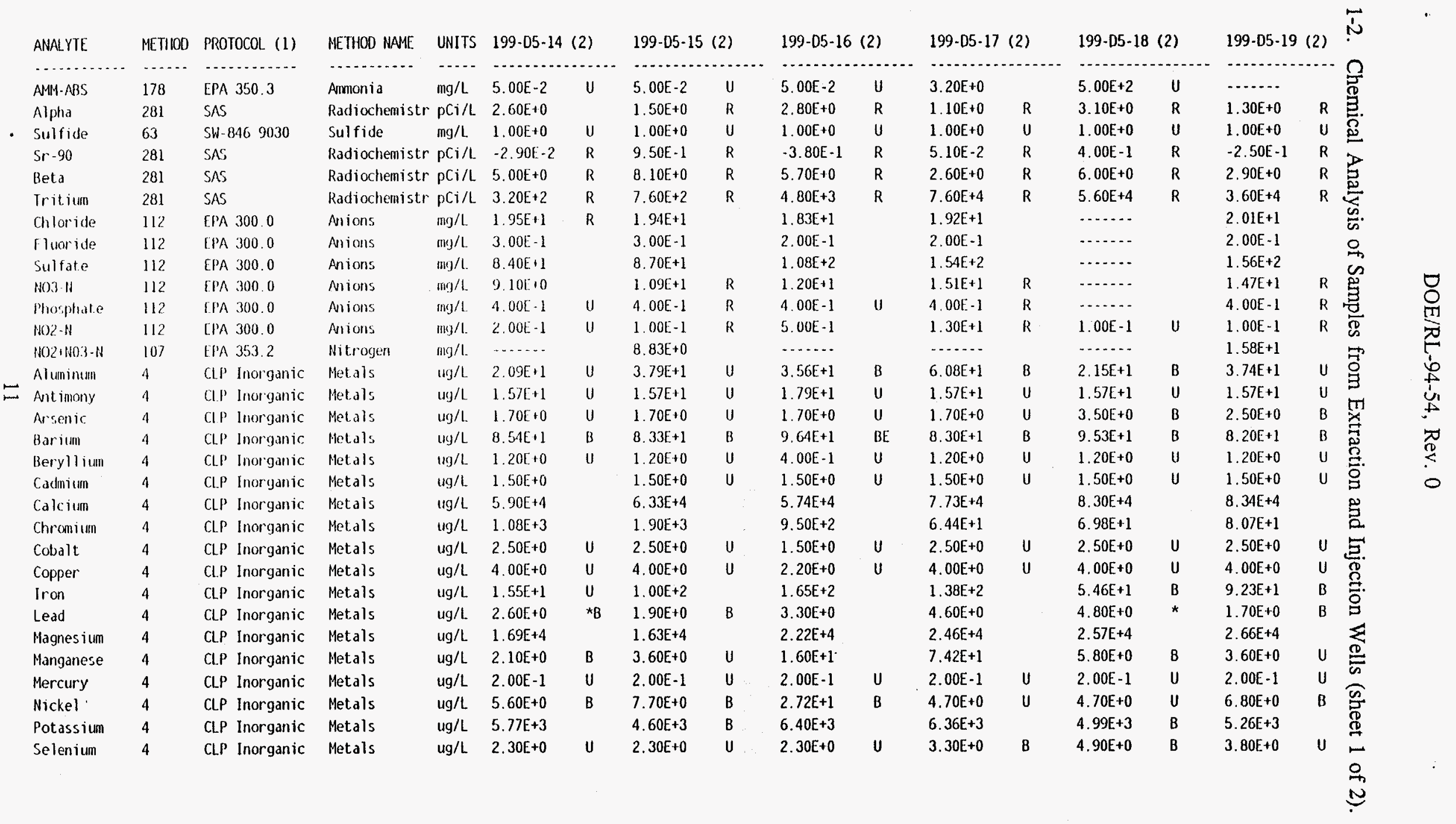


Table 1-2. Chemical Analysis of Samples from Extraction and Injection Wells (sheet 2 of 2)

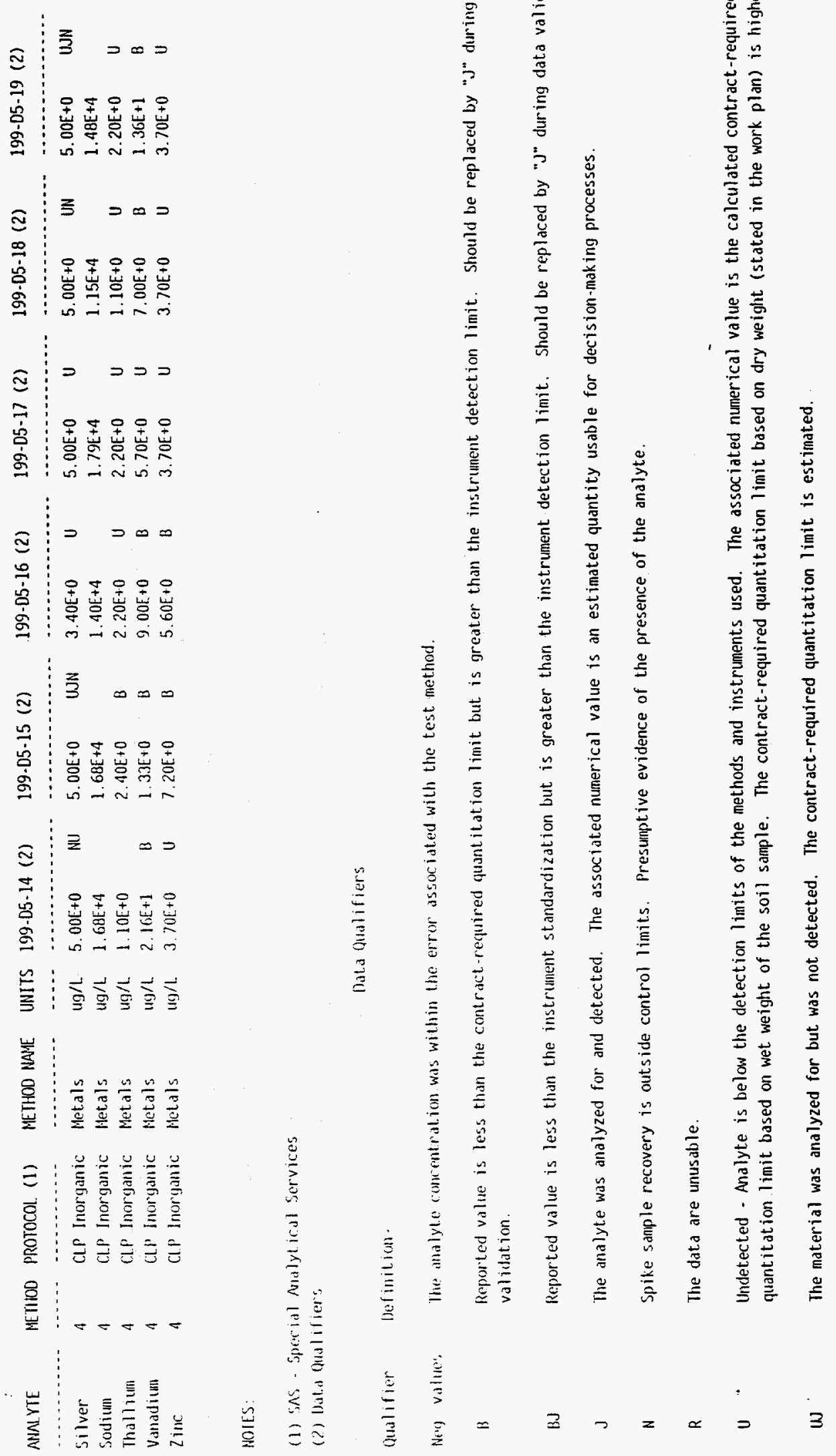


The highest concentrations of the chromium plume appear to be to the north of the 100-D Reactor (see Figure 1-2). Considering only the area within the $500 \mathrm{ppb}$ concentration isopleth, the plume volume is approximately $8.7 \mathrm{E}+07 \mathrm{~L}$. If the saturated aquifer thickness is assumed to be $20 \mathrm{ft}$ and the porosity is $10 \%$, then the mass of chromium within this plume is estimated at $106.8 \mathrm{lb}$. The soil-water distribution coefficient $\left(\mathrm{K}_{\mathrm{d}}\right)$ for chromium(VI) is 0 . Chromium(VI) is soluble and mobile and has little tendency to sorb to Hanford Site soils.

\subsection{WELL DRAWDOWN TESTS}

Table 1-1 summarizes the production information for the monitoring wells to be used as pumping or injection wells. The aquifer thickness and submerged screen length information were gathered from existing well as-builts, borehole logs, and the groundwater data base. The aquifer characteristics were developed from well development data, slug tests, and usability tests conducted in June 1994.

\subsection{PUMP-AND-TREAT TECHNOLOGIES}

\subsection{TECHNOLOGY DESCRIPTION}

Pump and treat involves the withdrawal of contaminated groundwater, treatment aboveground using appropriate pretreatment and treatment technologies (e.g., filtration and IX), and disposition of treated groundwater, usually by return to the aquifer. Two potential benefits of pump-and-treat technologies are that contaminant levels in the aquifer are reduced and selective return of treated groundwater can be used to limit plume expansion hydraulically.

Pump-and-treat system effectiveness depends on aquifer properties, contaminant characteristics, and treatment system operating parameters. Pump and treat has been shown to be effective at treating groundwater in which contaminants are relatively concentrated and mobile (i.e., pumpable). However, pump-and-treat technologies become less cost effective as primary contaminant concentrations decline. In these cases, greater volumes of groundwater must be circulated through the system to remove an equivalent contaminant mass.

While studies indicate that pump-and-treat technologies may not meet cleanup limits or federal or state ARARs (Cartwright 1991, EPA 1989), pump-and-treat technologies generally reduce contaminant levels and associated health/ecological risks and continue to operate until an acceptable risk reduction is met, a point of diminishing returns is reached, or natural attenuation exceeds active treatment. Pump-and-treat technologies are also used to contain contaminant plumes.

Pump-and-treat treatability test programs generally include an assessment of potential limitations of the aquifer/contaminant system on the success of pump and treat. Hydraulic limitations may affect the ability to withdraw contaminated groundwater from the aquifer at an effective pumping rate. The $\mathrm{D}$ Reactor plume may be extraction-limited due to the low transmissivities of the Ringold aquifer. 
Physical/chemical limitations affect the ability of pumped groundwater to carry primary contaminants with it, thereby facilitating extraction of the contaminants from the aquifer. Based on the mobility of chromium VI, this is not anticipated to be a problem in the D Reactor plume. Chromium VI concentrations will be monitored as part of the process monitoring sampling and analysis plan (SAP) (Appendix A). This information will be used to confirm effective removal of chromium VI. The effectiveness of pump-and-treat systems is also dependent on the overall composition of constituents. For example, sulfate, chloride, and phosphate can be preferentially removed over chromium VI.

\subsection{LABORATORY TESTS}

Laboratory bench-scale tests conducted using groundwater from 100-HR-3 wells recommended that the best method for removal of chromium VI is IX with a strong base IX resin (WHC 1993a). Several resins were evaluated, and DOWEX $21 \mathrm{~K}^{\mathrm{TS}}$, manufactured by Dow Chemical Co., was selected for these tests. Field pilot tests were recommended.

With respect to the treatment resins, the following was determined in laboratory tests.

- No pretreatment was required except a 5-micron prefilter before the IX unit to filter out suspended solids.

- For well D5-15, total chromium levels were measured at 2,025 ppb prior to treatment. After one cycle through the bench-scale IX column, total chromium levels were less than $20 \mathrm{ppb}$ and chromium VI levels were lower still. The goal of the laboratory tests was to treat chromium VI to less than $100 \mathrm{ppb}$. In the laboratory, breakthrough was observed at 1,100 column volumes (CV) for $100 \mathrm{ppb}$ and at $340 \mathrm{CV}$ for $50 \mathrm{ppb}$. (As used in this report, a column volume is the volume of the resin bed, including interstitial water, but not including headspace in the column above the resin bed.)

- Resin capacity was $2.79 \mu \mathrm{g}$ chromium per milligram of resin.

- No degradation of the resin was noted on the resin life after multiple cycles, and contaminant concentrations were below test goals.

- The IX was regenerated by the introduction of $4 \mathrm{M}$ sodium chloride onto the column bed. Cycling tests demonstrated no degradation of resin performance. The contaminant concentrations in the regenerate solution are typically several hundred thousand $\mathrm{ppb}$ chromium. The contaminant concentrations in the backflush water were significantly lower than in the regenerate solution. The amount of regenerate solution was one to two CVs. It contained uranium (VI) and was a mixed waste.

Regression analyses showed that there was no significant relationship between the breakthrough volume for chromium or chromium VI and fluctuations in the initial concentration of nitrate, sulfate, chloride, and carbonate; average pH: flow rates; products of carbonate and sulfate, chloride or nitrate; and the sum of nitrate, sulfate chloride and carbonate concentrations. Hence, variability in these parameters is not expected to have any significant impact during pilot tests. 


\subsection{TREATABILITY TEST PERFORMANCE AND DATA QUALITY OBJECTIVES}

Test performance objectives and data quality objectives (DQO) are used to clarify and guide the testing process and to ensure that the quality and quantity of data are sufficient to support remedy selection decisions. Test performance objectives identify information needs required to evaluate the pilot-scale pump-and-treat alternative. The DQOs link the information requirements with the intended data used to define the level of quality required for the measured variables. Data quality needs are defined by specifying precision, accuracy, representativeness, completeness, and/or comparability (PARCC) requirements.

\subsection{TEST PERFORMANCE OBJECTIVES}

The treatability goal for the IX system is to maintain injected effluent below $50 \mathrm{ppb}$, which is consistent with Washington Administrative Code (WAC) 173-200 for disposal to the ground and more conservative than the Model Toxics Control Act (MTCA) guidelines.

Objectives for Phase I and Phase II testing are as follows:

\section{Phase I Test Objectives:}

- Determine individual extraction well flow capacities and chromium VI concentration vs time

- $\quad$ Measure injection well capacities

- Estimate the zone of influence due to $8 \mathrm{~h} /$ day extraction

- Determine the effectiveness of the IX unit to consistently treat chromium VI to less than $50 \mathrm{ppb}$

- Verify IX column resin life vs flow rate/concentration of influent

- $\quad$ Refine operational configurations, requirements, and procedures

- Determine treated concentration levels of co-contaminants, i.e. reduced analyte list constituents

- Complete at least one resin canister cycle to evaluate sampling protocols and verify chromium break-through estimates

- Analyze spent resin for disposal/regeneration requirements, e.g. very low uranium may not yield a mixed waste designation

- Upgrade system for $24-\mathrm{h}$ and winter operations. 


\section{Phase II Test Objectives:}

- Determine long-term individual well flow rates and chromium VI concentration vs time

- Determine operational reliability and safety of the extraction, IX, and reinjection system for $24 \mathrm{~h} /$ day, 7 day/week operation

- Estimate zone of influence of $24 \mathrm{~h} /$ day, 7 day/week extraction well network

- Determine the efficiency of chromium VI mass removal in the groundwater plume

- $\quad$ Refine health and safety requirements

- Estimate cost/gal for treatment and the mass of chromium VI removed per unit time/volume treated per influent concentration.

\subsection{DATA QUALITY OBJECTIVES}

DQOs are qualitative and quantitative statements that specify the quality of data required to support remedial action decisions (EPA 1987). The DQOs are determined based on the end uses of the data to be collected. The end use of the treatability study data is to support the evaluation of pump and treat as a viable remedial action alternative. The DQOs have been developed to ensure that data collected will be of sufficient quality to evaluate the extraction, IX, and injection system.

Expected users of the test data include the following:

- DOE, Ecology, and EPA remedial project managers

- DOE, Ecology, and EPA unit managers

- Remedial investigation coordinators.

The test plan includes a combination of lower level (Levels I and II) and higher level (Level III) analyses to obtain the needed data in a cost-effective manner. Field screening and field analysis techniques (Levels I and II) will be used for daily monitoring requirements or measurements to ensure quick turnaround times required for process control. A limited number of confirmatory Level III analyses are identified for critical information (e.g., pre- and post-treatment concentrations of primary contaminants).

The DQOs are presented in Table 3-1. These DQOs are supplemented by the SAP (Appendix A). These DQOs may be refined as the test equipment designs are completed.

\subsection{ADDITIONAL DATA USES} following:

In addition to meeting specific treatability test objectives, data may also be used for the 
Table 3-1. Data Quality Objectives.

Activity Pilot-scale Treatability Test

Objectives Assess effectiveness, operating parameters, and costs to remove chromium VI from extracted groundwater.

Data Uses Demonstrate the feasibility of using the extraction, IX, and injection system to remediate the D Reactor chromium VI plume.

Appropriate Analytical Level or Implementation Guidelines

Field screening methods (eg. chromium VI HACH kit) will be used for process monitoring. Principle analytes and reduced analyte list constituents will be measured using Level III or V offsite analyses consistent with established groundwater monitoring methodology.

No validation will be required since only interim action decisions are being supported. These requirements are detailed in the sampling and analysis plan (SAP) (Appendix A) and the Quality Assurance Project Plan (QAPjP) (Appendix B).

Parameters to be Obtained

\section{Effectiveness:}

- Influent and effluent concentrations of chromium VI.

\section{Operating Parameters:}

- $\quad$ Process chemistry

- $\quad$ Flow rate - each extraction and injection well and IX system

- Total flow

- $\mathrm{pH}$, temperature

- Operating pressures - IX canister column and filter inlets/outlets, each injection and extraction well

- Water levels in injection and extraction wells

- Chromium VI concentration in individual extraction well approaches treatment goal of $50 \mathrm{ppb}$.

\section{Resource Needs:}

- $\quad$ Equipment/materials

- Personnel and maintenance requirements

- Waste volumes and characteristics

- Power and chemical usages

- Onstream factors

- Health and safety requirements 
DOE/RL-94-54, Rev. 0

Table 3-1. Data Quality Objectives (cont).

Activity Pilot-scale Treatability Test

Required Detection or Measurement Limits

- $\quad$ Effectiveness

Analytical methods for chromium VI must be able to detect expected effluent concentrations to less than $50 \mathrm{ppb}$. Accuracy should be sufficient to support a maximum $50 \mathrm{ppb}$ treatment goal. Goals for field screening with the HACH kit are to have a detection limit capability of $40 \mathrm{ppb}$, precision $\pm 20 \%$, and accuracy $\pm 75-125 \%$. The following are DQOs for offsite analyses:

PRINCIPAL ANALYTES

\begin{tabular}{|c|c|c|c|c|c|}
\hline$\underline{\text { Parameter }}$ & $\underline{\text { Level }}$ & Method & $\mathrm{CRDL}^{\mathrm{a}}$ & Precision & $\underline{\text { Accuracy }}$ \\
\hline Chromium VI & III & $7196^{b}$ & 10 & $\pm 20 \%$ & $75-125 \%$ \\
\hline $\begin{array}{l}\text { Chromium } \\
\text { (total) }\end{array}$ & III & $200.7,218.1$ or $218.2^{c}$ & 20 & $\pm 25 \%$ & $75-125$ \\
\hline
\end{tabular}

REDUCED ANALYTE LIST

\begin{tabular}{|llllll|}
\hline Parameter & Level & Method & CRDLa & Precision & Accuracy \\
ICP Metals & III & & ug/L & & \\
Antimony & & $c$ & 60 & $\pm 20 \%$ & $75-125 \%$ \\
Barium & & $c$ & 200 & $\pm 20 \%$ & $75-125 \%$ \\
& $\mathrm{c}$ & 5 & $\pm 20 \%$ & $75-125 \%$ \\
Beryllium & $\mathrm{c}$ & 5000 & $\pm 20 \%$ & $75-125 \%$ \\
Cadmium & $\mathrm{c}$ & 50 & $\pm 20 \%$ & $75-125 \%$ \\
Calcium & $\mathrm{c}$ & 25 & $\pm 20 \%$ & $75-125 \%$ \\
Cobalt & $\mathrm{c}$ & 100 & $\pm 20 \%$ & $75-125 \%$ \\
Copper & $\mathrm{c}$ & 15 & $\pm 20 \%$ & $75-125 \%$ \\
Iron & $\mathrm{c}$ & 40 & $\pm 20 \%$ & $75-125 \%$ \\
Magnesium & $\mathrm{c}$ & 5000 & $\pm 20 \%$ & $75-125 \%$ \\
& $\mathrm{c}$ & 10 & $\pm 20 \%$ & $75-125 \%$ \\
Manganese & $\mathrm{c}$ & 5000 & $\pm 20 \%$ & $75-125 \%$ \\
Nickel & $\mathrm{c}$ & 50 & $\pm 20 \%$ & $75-125 \%$ \\
& $\mathrm{c}$ & 20 & $\pm 20 \%$ & $75-125 \%$ \\
Potassium & $\mathrm{c}$ & & $\pm 20 \%$ & $75-125 \%$ \\
Silver & $\mathrm{c}$ & & & $75-125 \%$ \\
Sodium & & & & \\
Vanadium & & & & \\
Zinc & & & &
\end{tabular}


Table 3-1. Data Quality Objectives (cont).

\begin{tabular}{|c|c|c|c|c|c|}
\hline \multicolumn{6}{|c|}{ Activity $\quad$ Pilot-scale Treatability Test } \\
\hline \multirow{2}{*}{$\begin{array}{l}\text { Anions } \\
\text { Ammonia }\end{array}$} & \multicolumn{2}{|c|}{ III · } & \multicolumn{3}{|l|}{$\mathrm{ug} / \mathrm{L}$} \\
\hline & & $350.3^{d}$ & 30 & $\pm 20 \%$ & $75-125$ \\
\hline Chloride & & EPA 300.2 modified $^{e}$ & 10,000 & $\pm 20 \%$ & $75-125$ \\
\hline Fluoride & & EPA 300.2 modified $^{e}$ & 100 & $\pm 20 \%$ & $75-125$ \\
\hline \multirow[t]{2}{*}{ Nitrate } & & EPA 300.2 modified $^{e}$ & 100 & $\pm 20 \%$ & $75-125$ \\
\hline & & EPA 300.2 modified $^{2}$ & 500 & $\pm 20 \%$ & $75-125$ \\
\hline Phosphate & & EPA 300.2 modified $^{e}$ & 2,000 & $\pm 20 \%$ & $75-125$ \\
\hline $\begin{array}{l}\text { Sulfate } \\
\text { Sulfide }\end{array}$ & & $9030^{b}$ & 5 & $\pm 20 \%$ & $75-125$ \\
\hline Gross Alpha & $\mathrm{v}$ & $900.0^{c}$ & 3 & $\pm 35 \%$ & $30-105 \%$ \\
\hline Gross Beta & $\mathrm{V}$ & $900.0^{\mathrm{c}}$ & 4 & $\pm 35 \%$ & $30-105 \%$ \\
\hline Tritium & $\mathrm{v}$ & Water $906.0^{f}$ & $400 \mathrm{pCi} / \mathrm{L}$ & $\pm 20 \%$ & $75-125 \%$ \\
\hline Strontium-90 & $\mathrm{v}$ & Water $906.0^{\mathrm{f}}$ & $10 \mathrm{pCi} / \mathrm{L}$ & $\pm 20 \%$ & $75-125 \%$ \\
\hline \multicolumn{6}{|c|}{ - $\quad$ Operating Parameters } \\
\hline \multicolumn{6}{|c|}{$\begin{array}{l}\text { Process chemistry will be measured primarily to detect significant and/or unanticipated } \\
\text { secondary impacts on system operation and efficiency. Analytical protocols will follow } \\
\text { established vendor standards, industrial standards, or EPA practices. Other operating } \\
\text { parameters will be measured as follows: }\end{array}$} \\
\hline \multicolumn{3}{|c|}{$\underline{\text { Parameter }}$} & $\underline{\text { Instrument }}$ & $\underline{\text { Range }}$ & Accuracy \\
\hline \multirow{2}{*}{\multicolumn{3}{|c|}{$\begin{array}{r}\text { Flow Rate, IX } \\
\text { Wells }\end{array}$}} & meter & $0-80 \mathrm{gpm}$ & $\pm 0.5 \mathrm{gpm}$ \\
\hline & & & meter & $0-30 \mathrm{gpm}$ & $\pm 0.5 \mathrm{gpm}$ \\
\hline \multicolumn{3}{|c|}{ Total Flow } & totalizer & N/A & $\pm 10 \%$ \\
\hline \multicolumn{3}{|c|}{$\mathrm{pH}$} & meter & $0-14$ & $\pm 0.1 \mathrm{gal}$ \\
\hline \multicolumn{3}{|c|}{ Temperature } & $\begin{array}{l}\text { thermocouple or } \\
\text { thermometer }\end{array}$ & $0-100^{\circ} \mathrm{C}$ & $\pm 1^{\circ} \mathrm{C}$ \\
\hline \multicolumn{3}{|c|}{ Water Levels } & transducer & $0-50$ psi & $\pm 1 \mathrm{psi}$ \\
\hline \multicolumn{3}{|c|}{ Differential Pressure } & transducer & $0-30$ psi & $\pm 0.5 \mathrm{psi}$ \\
\hline \multicolumn{6}{|c|}{ Point pressure } \\
\hline \multicolumn{3}{|c|}{ Injection Well } & transducer & $0-50$ psi & $\pm 1 \mathrm{psi}$ \\
\hline \multicolumn{3}{|c|}{ Extraction Well } & transducer & $0-25 \mathrm{psi}$ & $\pm 1 \mathrm{psi}$ \\
\hline
\end{tabular}


Table 3-1. Data Quality Objectives (cont).

Activity Pilot-scale Treatability Test

- $\quad$ Resource Needs

Resources will be monitored in accordance with normal record-keeping practices (e.g., inventory, manhours) specific to each resource type.

Critical Samples or Values

- Chromium VI concentrations in influent and effluent streams to be protective of $<50 \mathrm{ppb}$ effluent goal.

- Radiological concentrations in spent IX resins.

- $\quad$ Extraction well pressure (water level/drawdown)

- Injection well pressure (water level/mounding)

- Operating costs (e.g., materials, power, personnel).

- Waste disposal costs.

Constraints

- It is necessary that breakthrough be measured in a timely manner for chromium VI so as not to exceed the $50 \mathrm{ppb}$ effluent goal.

- $\quad$ Representative samples are required of influent and effluent streams and spent resin.

- Continued biannual groundwater monitoring is required to verify that the pumped water is representative of site conditions.
a. $\mathrm{CRDL}=$ contract required detection limit
b. EPA 1986, SW-846 Method.
c. USEPA, CLP Method (EPA 1991)
d. Methods for Chemical Analysis of Water and Wastes (Kopp and McKee 1983).
e. Determination of Inorganic Anions in Aqueous and Solid Samples by Ion Chromatography (Lindahl 1984).
f. Prescribed Procedures for Measurement of Radioactivity in Drinking Water (Krieger and Whittaker 1980). 
- Defining interim action designs and objectives

- Determining monitoring needs for interim actions

- Identifying additional treatability test needs

- $\quad$ Providing data to evaluate the technology for other Hanford sites.

\subsection{APPLICABLE RELEVANT -AND APPROPRIATE REQUIREMENTS}

Location-specific ARARs for the 100-HR-3 Operable Unit are identified in the 100 Area Feasibility Study Phases I and II (DOE-RL 1992b). Chemical-specific ARARs for the 100-HR-3 Operable Unit are identified in the LFI Report for the 100-HR-3 Operable Unit (DOE/RL 1993).

This treatability test will generate chromium-contaminated spent IX resins. These resins will be periodically replaced or regenerated. The spent resins or the regenerate liquid may be a hazardous waste subject to the Hazardous Waste Management Act. Such wastes will be handled as investigationderived waste as described in the Waste Control Plan (WCP, BHI 1994) for this treatability test. The WCP (BHI 1994) will be approved by RL and the regulatory agencies.

The treated groundwater, containing up to $50 \mathrm{ppb}$ chromium, will be reinjected to the aquifer. The treated groundwater will also contain nitrate which may be above the drinking water standards. Nitrate is currently detected in the extraction wells at concentrations at or slightly above the drinking water standard of $10 \mathrm{ppm}$. The IX system is expected to remove some of the nitrate from the groundwater. There are currently no other contaminants of concern detected in the extraction wells (199-D5-14, -15, and -16) above drinking water standards. However, both tritium and ${ }^{90} \mathrm{Sr}$ have been detected nearby at concentrations above drinking water standards. Operation of the extraction system may draw tritium and/or ${ }^{90} \mathrm{Sr}$ into the IX system. Because the IX system likely will not remove ${ }^{90} \mathrm{Sr}$ or tritium, these contaminants may be reinjected, at levels above state discharge limits, into a portion of the aquifer already contaminated with these constituents. The Tri-Party Agreement Change Control Form M-15-93-02 provides that "Treated effluent containing contaminants above State water quality standards can be disposed of to the soil column or aquifer."

\subsection{TREATABILITY TEST DESIGN AND OPERATING REQUIREMENTS}

This section describes design and operating requirements for Phase I and II tests. The activities described in this section are designed to fulfill test performance objectives and DQOs discussed in Chapter 3.0.

\subsection{PROCESS DESCRIPTION}

Conceptual process flow diagrams of the extraction, IX, and injection system to be used for Phase I and II testing are shown in Figures 4-1 and 4-2. Standard operating procedures will be prepared as a separate document. 


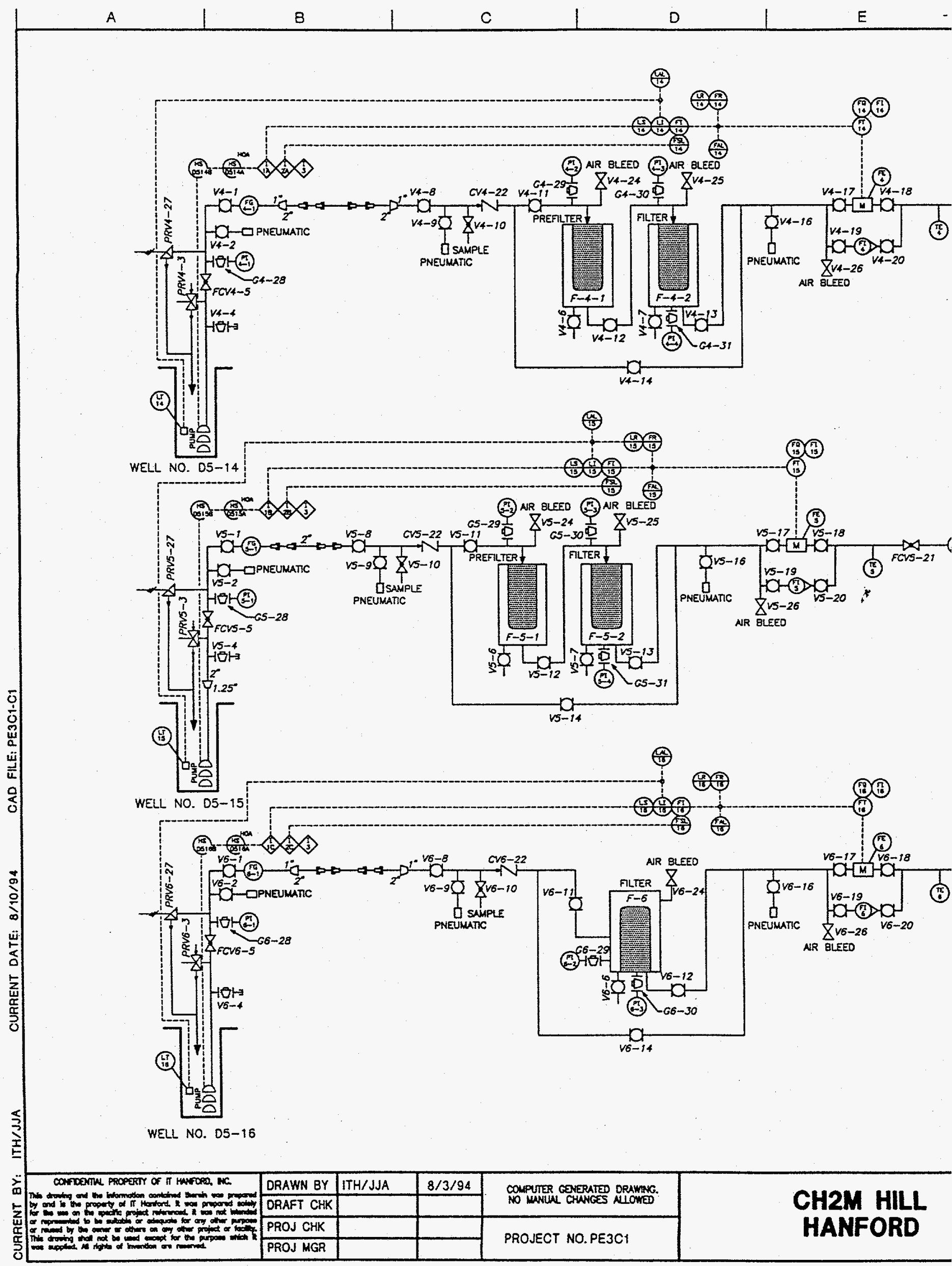




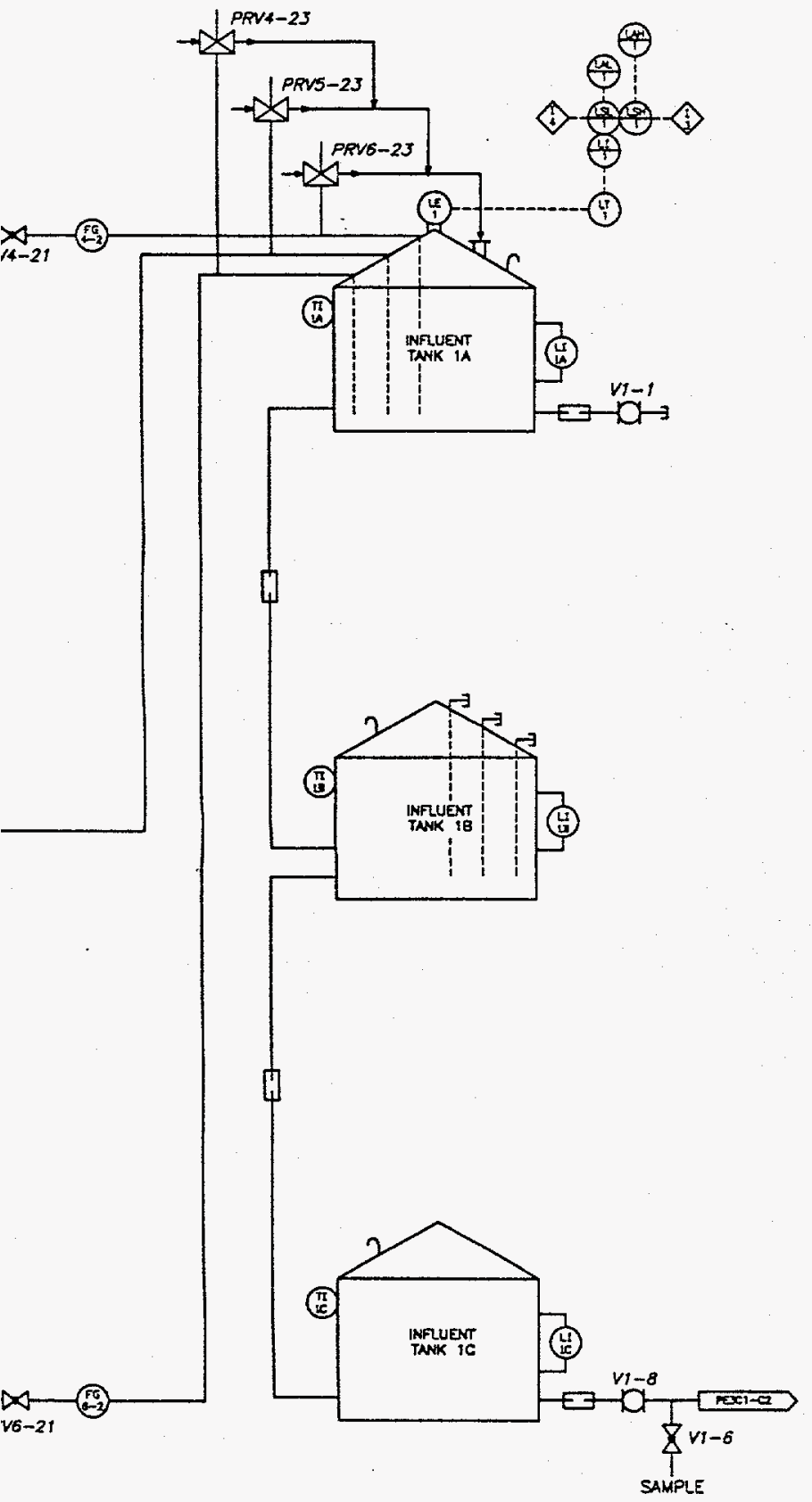
Ion Exchange, and Injection System (sheet 1 of 2).

\begin{tabular}{|c|c|c|}
\hline & FRST & succosedic \\
\hline$E$ & & EDERT (SENSOR) \\
\hline$F$ & FOW RATE & \\
\hline 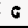 & & auss \\
\hline 1 & INTERROCX (REAM) & IMOCATOR \\
\hline$L$ & LEVI & \\
\hline $\mathbf{p}$ & PRESSUIfE & \\
\hline$T$ & TEPGRATURE & RUNSUMER \\
\hline
\end{tabular}

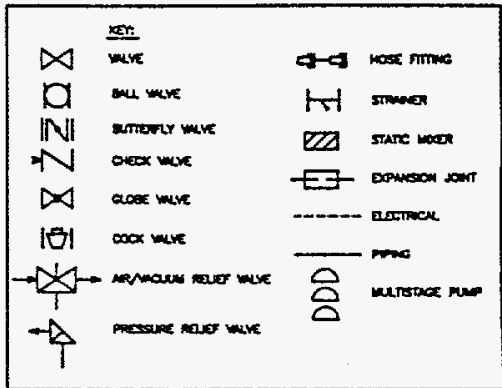

(1)

(1) .

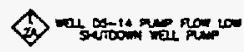

今.

(5)

(1) sencoming

(i)

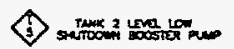

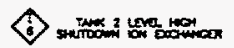

4

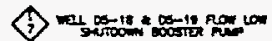

(1)

(1)

5 


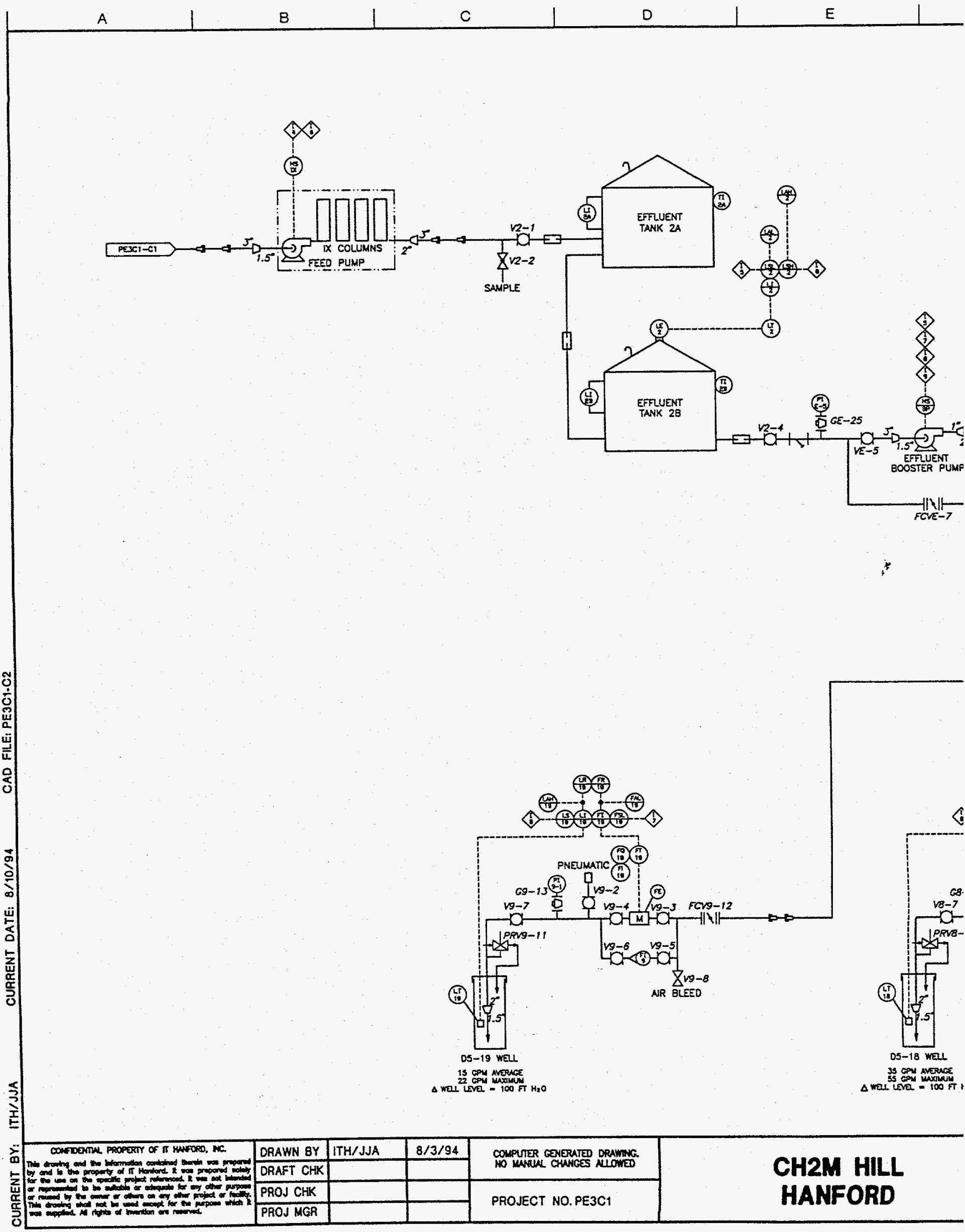




\begin{tabular}{ll|l|l|l|l|}
$F$ & D & DOE/RL-94-54, Rev. 0
\end{tabular}.

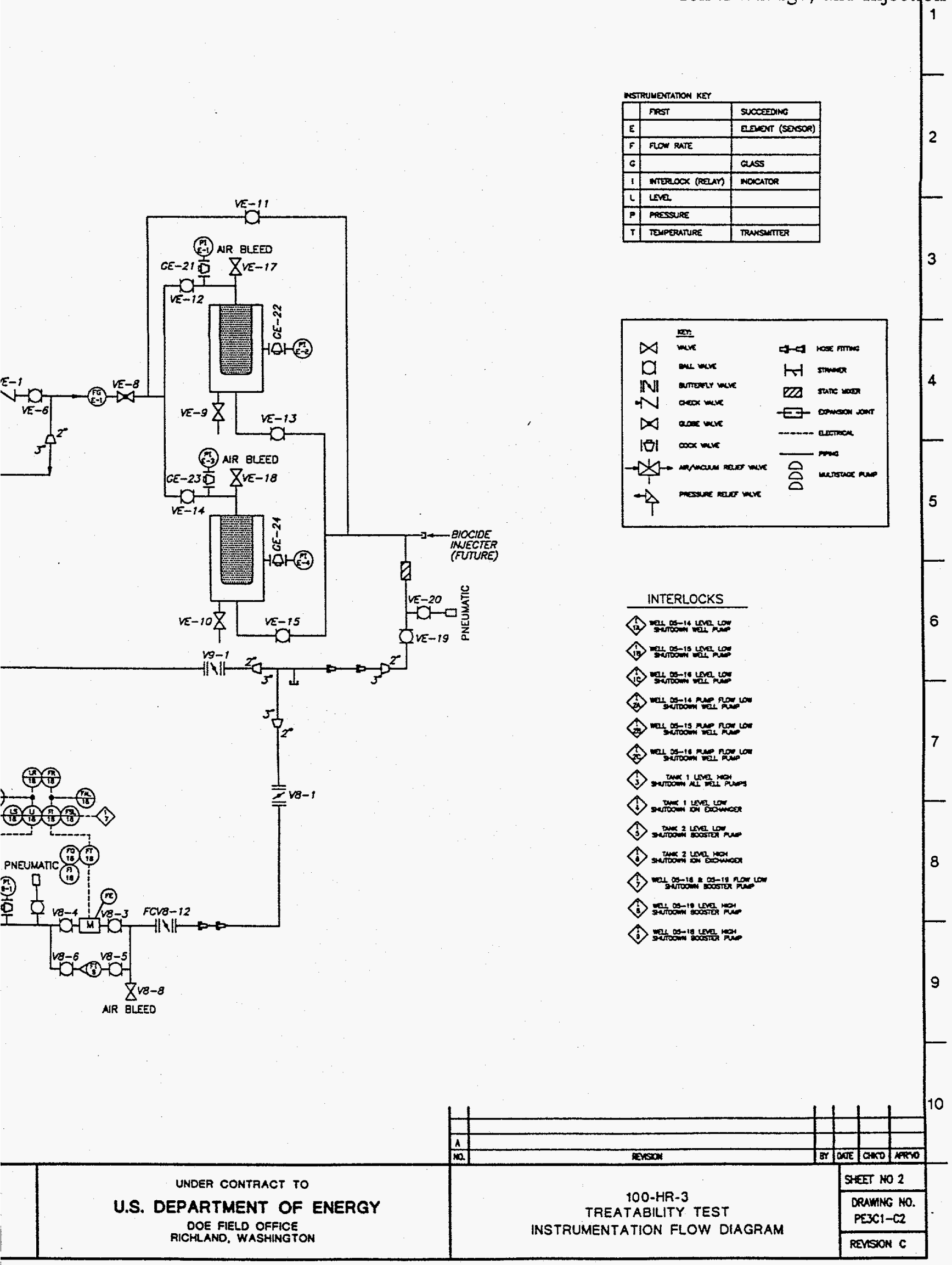




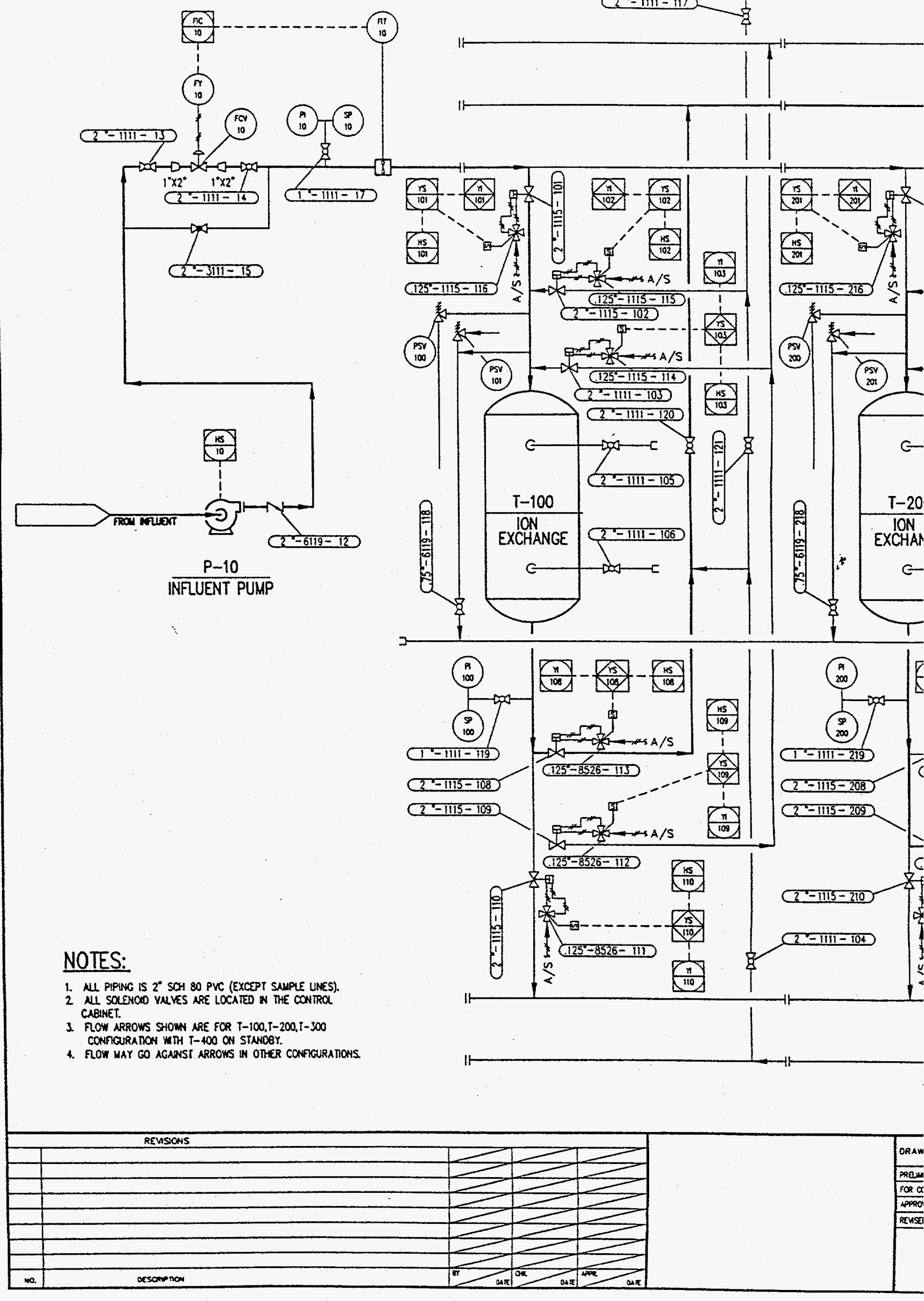


The IX system will be run on a nominal 8-h/day basis, 5 days/week, at a flow rate of 25 to $60 \mathrm{gal} / \mathrm{min}$ depending on the capacity of the wells being pumped. Prior to startup of the system a readiness review will be performed using the process described in Environmental Investigation Instruction (EII) 1.13, "Environmental Readiness Review" (WHC 1988b).

Water will be pumped through an influent line and 5-micron pre-filters to influent storage tank(s). The purpose of the influent tanks is to provide storage capacity to compensate for different flow rates between the extraction wells and the IX system.

Water is pumped from the influent tanks to an IX unit. The IX unit for this test is being fabricated by Resource Technologies Group, Inc. (RTG). (Lakewood, CO). RTG won the bid through a competitive bid process (Equipment Specifications are included in Appendix C). The IX unit will be tested by RTG prior to shipment and standard acceptance tests will be performed at the test site by Hanford Site Personnel.

Acceptance test procedures will be prepared in accordance with Westinghouse Hanford Company (WHC) Standard Engineering Practices (WHC-CM-6-1, Appendix M, [WHC 1988a]). Piping, electrical connections, and integration of the system with extraction and injection pumps will be performed at the test site by Hanford Site personnel.

The IX unit (see Figure 4-2) has a nominal design capacity of $50 \mathrm{gal} / \mathrm{min}$, but can be operated as low as $25 \mathrm{gal} / \mathrm{min}$ or as high as $60 \mathrm{gal} / \mathrm{min}$. Flow meters will be used to monitor the flow rates from the extraction wells and in the IX unit. Totalizers will be used to measure the volume of water extracted from each well and processed by the IX unit.

The IX unit will be skid-mounted and consists of four IX columns that can be operated in any sequence. Normally, three columns will operate simultaneously in a lead lag-lag configuration and a fourth column will serve as backup. Columns will be manifolded such that they can be operated in any sequence and with only two or up to four columns operating simultaneously. Based on laboratory test results, the first column in the series is expected to remove the bulk of the chromium in the groundwater and the second and third column will remove residual concentrations. When breakthrough occurs, the column will be taken out of service. Groundwater will then be pumped directly to one of the other columns and the backup column will be put on line.

This will allow the system to continue to operate while spent resin from the "first column" is replaced or regenerated. Regeneration capabilities will be available as part of the system. If an acceptable repository and treatment strategy can be found for regeneration solutions, the system may be operated with regenerated resin; otherwise, resin will be replaced when exhausted.

The regeneration process would consist of a backwash pump and regeneration tank. If used, resin would be regenerated using a four-molar sodium chloride solution. Regenerate solution would be pumped through the IX resin column and into storage tanks or haul trucks. Regenerate solution would then be handled as specified in the WCP (BHI 1994).

The IX unit will be controlled by a programmable logic controller (PLC) with air-operated control valves with electric override. All piping is schedule 80 PVC. The IX will have sampling valves on the system influent line and effluent line of each column for grab samples. 
After treatment, water will be pumped into an effluent storage tank(s). The purpose of the effluent tank(s) is to ensure that an uninterrupted effluent flow can be pumped to the injection well network. From the tank, effluent will be pumped through a 5-micron polishing filter. Biocide will then be injected into the stream to prevent biofouling. Finally, the water will be pumped 500 to 600 $\mathrm{m}$ to injection wells D5-17, D5-18 and D5-19 (see Figure 1-2).

These injection wells were selected because (1) they are near the extraction wells, (2) they are upgradient from the extraction wells, (3) they are in the source area of the tritium plume so tritium will be reinjected to the source area, and (4) estimated well capacities exceed extraction well capacities.

Water levels will be continuously monitored by means of pressure tranducers placed immediately above the well pump in each extraction well and at mid-screen depth in each injection well. The transducers will send input to data loggers located at the meter control panel. A maximum drawdown limit for each extraction well will be established prior to extraction well start-up to prevent pump cavitation. A maximum fluid level for each injection well will be established prior to injection well start-up to prevent excessive pressure on the bentonite seal portion of the well.

Flow rates and operating times for extraction wells and injection wells will be recorded daily.

\subsection{PHASE I OPERATION}

\subsubsection{General Operation}

Phase I operations are scheduled to begin by August 31,1994 . In Phase I operations, well D5-15 will be pumped nominally $8 \mathrm{~h} /$ day, 5 days/week for an extended time during which D5-14 and D5-16 will be monitored for potential drawdown. (Water elevations in numerous area wells are also measured on an independent monthly routine.) If sustained flow from well D5-15 is less than the minimum flow requirements of the IX unit, an inventory will be built up in the influent tanks prior to start-up of the IX unit.

Following an extended period of pumping from well D5-15, wells D5-14 and D5-16 will be manifolded to the influent tanks to provide additional influent capacity and chromium plume capture and treatment. As stated in Section 1-4, these wells are expected to be less productive than D5-15 and have lower concentrations of chromium. The wells will be pumped at their maximum sustainable rate to obtain additional performance data on the extraction, IX, and injection system.

Data on the effectiveness of the treatment process will be collected throughout the test program. If the IX unit does not achieve the desired treatment levels, operating parameters will be changed or the IX unit will be modified until treatment is either successful or is determined to be ineffective.

\subsubsection{Specific Operations Monitoring}

To achieve the hydraulic objectives of Phase I operations, the following field requirements are imposed. 
- Record water-level changes using a logarithmic scale at the start and end of each pumping and injection cycle

- . Record flow rates in the extraction and injection wells (every $10 \mathrm{~min}$ for $1 \mathrm{~h}$; every $30 \mathrm{~min}$ thereafter at the start of an extraction or injection operation)

- Vary pumping rates and schedules. The following guidelines are proposed:

(1) Extract groundwater using the standard schedule of a nominal 8-h-on / 16-h-off;

(2) Inject groundwater using the standard injection schedule of continuous operation, 24-h/day / 5-days-per-week (this will minimize hydraulic head build-up, protecting the integrity of the well). Initial head build-up should be incremented in 5- to 10 -ft segments, one segment per day, until the maximum recommended head is achieved;

(3) Use other pumping and injection rates and schedules as testing proceeds and well operation and conditions warrant. For purposes of well integrity, the imposed hydraulic head in the injection wells should not exceed $10 \mathrm{lbs} / \mathrm{in}^{2}$ at the top of the well screen.

\subsection{PHASE II OPERATION}

\subsubsection{General Operation}

Phase II testing will commence upon system expansion to $24 \mathrm{~h} /$ day, 7 day/week operational capability and system winterization. This is scheduled for mid November, 1994 . Phase II will be similar to Phase I in that the same IX unit and resin will be used and groundwater will be extracted from the same wells (D5-14, D5-15, and D5-16).

Water pumped from the three wells will be manifolded independently to the influent tanks. The IX unit will be operated as necessary to treat the groundwater generated by continuous pumping. The extraction well network will pump to the influent tanks overnight to provide sufficient reserve to operate the IX unit at capacity for a nominal 8-h/day shift. Modifications to this procedure will be made as necessary based on flow rates determined in pump tests (section 1.4) and results of Phase I testing. The IX columns will be operated as described for Phase I tests.

\subsubsection{Specific Operations Monitoring}

Phase II operations monitoring will focus on confirming and expanding the estimates and interpretations developed during Phase I operations. In addition, aquifer parameters will be evaluated to estimate whether the zone of capture of the extraction will network under continuous 24-h/day, 7 day/week operation. Chromium VI concentrations will be monitored with time and flow rates to evaluate if an optimum extraction rate per well is apparent and/or if a cyclic extraction schedule would increase chromium VI removal. Injection well water levels will be closely monitored to minimize well head pressure on the bentonite seals and to evaluate water mounding associated with long-term continuous injection. 


\subsection{SYSTEM INTERRUPTIONS}

In Phase I and Phase II operation of the IX system may be interrupted for valid technical reasons such as (1) to modify and upgrade the components or controls of the system; (2) to evaluate the operational mode of "pulsing" the extraction system by switching the system off for sufficient time to "rewet" the sediments in the cone of depression; (3) to conduct various tests/remediation of the extraction, injection, or treatment systems; (4) to move the entire system to another area of interest; or (5) if the influent concentration approaches the treatment concentration goal of $50 \mathrm{ppb}$ and it is no longer economically nor technically feasible to continue system operation at that well network.

System interruptions described above or other changes to operation or requirements defined in this test plan will be discussed and an agreement reached with the Unit Managers prior to being initiated. System interruptions for general maintenance, minor repairs, or to meet the requirements of this test plan will be conducted without prior notice to the Tri-Parties.

\subsection{PROCESS WASTE MANAGEMENT}

Secondary waste will be disposed and/or stored onsite at locations agreed to by the three parties. The WCP (BHI 1994) provides information on the handling and disposition of wastes generated during treatability testing. The regulatory agencies are required to approve the WCP (BHI 1994) prior to initiating the pilot-scale test.

The test will generate secondary wastes primarily through the replacement of spent resins, potential backflushing, conditioning or rinsing of the resins in the IX columns, and replacing filter cartridges. All waste will be disposed of per WHC policy for onsite disposal according to waste type (WHC 1988b).

\subsection{PILOT-SCALE TREATABILITY TEST SAMPLING AND MONITORING}

\subsubsection{Process Monitoring}

Successful operation during Phase I and Phase II testing will be dependent on a quick-turnaround sampling and analysis program to determine when breakthrough of the resin occurs. Process monitoring will be performed to control and operate the treatment process and to gather performance data.

Quick-turn-around samples will be taken as frequently as needed to establish control parameters and system performance in the early stages of Phase I and Phase II operations. Online chromium monitors are being investigated. These may be used during Phase II testing. Radiation monitoring will be performed for ion resin, but measurable radioactivity levels are not anticipated from the D-Reactor plume.

After system performance is established, screening samples will continue to be taken no less than once per day. Samples will be taken from each extraction well influent line and the inlet and outlet of the lead IX column. These samples will be screened using $\mathrm{HACH}$ kits for chromium VI. 
The effectiveness of the IX unit will be primarily demonstrated through laboratory Level III and $\mathrm{V}$ chemical analyses of process samples. These samples will be taken at a frequency of no less than once per week. Samples from the influent and effluent from the lead IX column will be taken. The long-term frequency of sampling will be related to the observed rate of change of contaminant concentrations in the untreated groundwater and the estimated breakthrough (based on laboratory tests $340 \mathrm{CV}$ for $50 \mathrm{ppb}$ [see Section 2.2] for the IX columns. Appendix A of this test plan presents the process SAP that will be followed.

Pressure drops across IX columns will be monitored to assess the buildup of suspended solids on the resin and the potential need for resin regeneration or replacement. Solids generation and accumulation in different parts of the IX unit, an accounting of all secondary waste generation, maintenance, and chemical addition rates and volumes will be documented in the field log book. The volume of groundwater pumped to the IX unit and reinjected into the aquifer will be measured with flowmeters/totalizers.

\subsubsection{Groundwater Monitoring}

Field activities will be conducted to monitor impacts of the test to the local upper unconfined aquifer. Current monitoring activities in the 100-HR-3 groundwater operable unit, which include water table level measurements and groundwater sampling for a reduced analyte list, will be continued on the biannual schedule. Active injection wells will be dropped from the biannual sampling program since influent analyses are available.

\subsection{REQUIREMENTS}

In addition to requirements identified in this document, all work will be performed in accordance with the following applicable documents and procedures.

- WHC-EP-0383, Environmental Engineering, Technology, and Permitting Function Quality Assurance Program Plan (WHC 1990)

- WHC-CM-7-7, Environmental Investigations and Site Characterization Manual (WHC 1988b)

- EII 1.5 "Field Logbooks"

- EII 5.1 "Chain of Custody"

- EII 5.4 "Field Cleaning and/or Decontamination of Equipment"

- EII 5.8 "Groundwater Sampling"

- EII 5.11 "Sample Packaging and Shipping"

- EII 10.3 "Purgewater Management"

- WHC-CM-7-8, Vol. 4, Environmental Engineering and Geotechnology Function Procedures (WHC 1992)

- Section 2.2, "Groundwater Quality Control Sampling" 
- Section 2.5, "Temperature Control of Groundwater Sample Storage Refrigerators"

- Section 5.1, "Groundwater Measuring and Test Equipment (M\&TE) Calibration by User"

- Section 5.2, "Groundwater M\&TE Calibration by WHC Standards Laboratory"

\subsection{QUALITY ASSURANCE REQUIREMENTS}

The quality assurance documents that cover the test activities are the Quality Assurance Manual (WHC 1988c) and the Environmental Engineering, Technology, and Permitting Function Quality Assurance Program Plan (WHC 1990). Data quality will be controlled by the QAPjP in Appendix B of this test plan. frequency:

Quality control samples for Level III and V analyses will be collected at the following

- $\quad$ One duplicate from one well for every four samples taken

- $\quad$ One split sample from one well for every four samples taken.

\subsection{HEALTH AND SAFETY}

All field work conducted under this treatability test plan will be in accordance with the "100HR-3 Operable Unit Health and Safety Plan" (DOE-RL 1988, Appendix B) and an approved Hazardous Waste Operations Plan (HWOP). The HWOP will contain all health and safety requirements in accordance with the following:

- WHC-CM-1-6, WHC Radiological Control Manual (WHC 1993b)

- $\quad$ WHC-IP-0718, Health Physics Practices Manual (WHC 1988d)

- $\quad$ WHC-CM-4-3, Industrial Safety Manual (WHC 1987)

- WHC-CM-7-5, Environmental Compliance Manual (WHC 1988e)

- $\quad 29$ Code of Federal Regulations (CFR) 1910.120.

\subsection{SUPPORTING DOCUMENTS}

Supporting documents include the laboratory test report (WHC 1993a), the Investigation/Corrective Measures Study Work Plan for the 100-HR-3 Operable Unit (DOE-RL 1992a), SAP (Appendix A), and QAPjP (Appendix B). These supporting plans will be applicable to all test work scope performed by WHC within the 100-HR-3 Operable Unit. Community relations activities in support of this treatability test will be performed as specified in the Tri-Party Agreement (Ecology et al. 1989).

All work will be performed in accordance with the following documents/permits applicable to this project. 
- $\quad$ Radiation Work Permit: Addresses potential radioactive hazards; identifies protective clothing requirements and training.

- HWOP: Addresses and mitigates site-specific health and safety hazards; provides for emergency response and sets forth personnel training requirements necessary for site entry.

- Safety Analysis Plan: Addresses global safety and environmental issues associated with plant operations (e.g., impacts resulting from tank failure) and specifies appropriate safety requirements for mitigation of these impacts.

- Standard Operating Procedures: Establishes the process and procedures necessary for safe and effective operation of the treatment system. Identifies steps to be followed in the performance of the treatability test with sufficient detail to allow the operator to operate the equipment and collect the samples with minimum supervision.

\subsection{REPORTS}

A test report will be prepared summarizing the results of the test. The format of the report will be based on the suggested outline for treatability test reports provided in the Guide for Conducting Treatability Studies under CERCLA (EPA 1992). Project briefings will be given at unit manager meetings between DOE, EPA, and Ecology.

\subsection{SCHEDULE}

Figure 8-1 shows the schedule for planning and performing the test. The test is expected to be initiated by August 31,1994. Phase II will commence after attainment of Phase I objectives or by November 11, 1994 unless extended by the Unit managers.

This schedule is contingent on the demonstration of adequate well capacity, the approval of the well recommendations and WCP (BHI 1994), and addressing all safety concerns.

\subsection{PROGRAM ORGANIZATION}

After July 1, 1994, the test will be the responsibility of the Hanford Environmental Contractor. Figure 9-1 shows the organizational structure for the treatability test. Due to ongoing transition issues and reassignment of responsibilities between WHC and Bechtel Hanford, names are not given and specific titles may change. However, whatever the title, test responsibilities (Table 9-1) corresponding with each block in Figure 9-1 will be required for the test to be successful. 


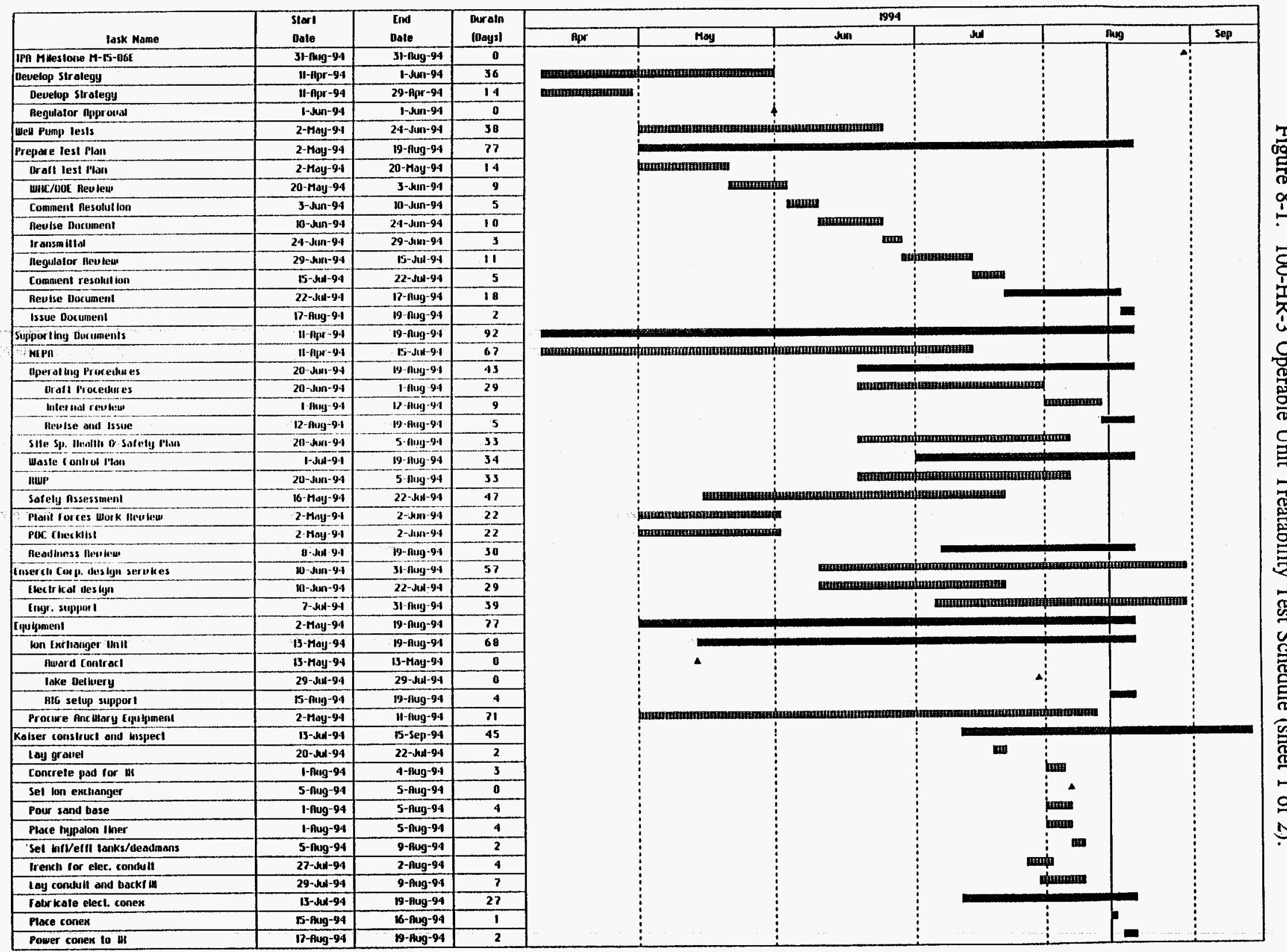




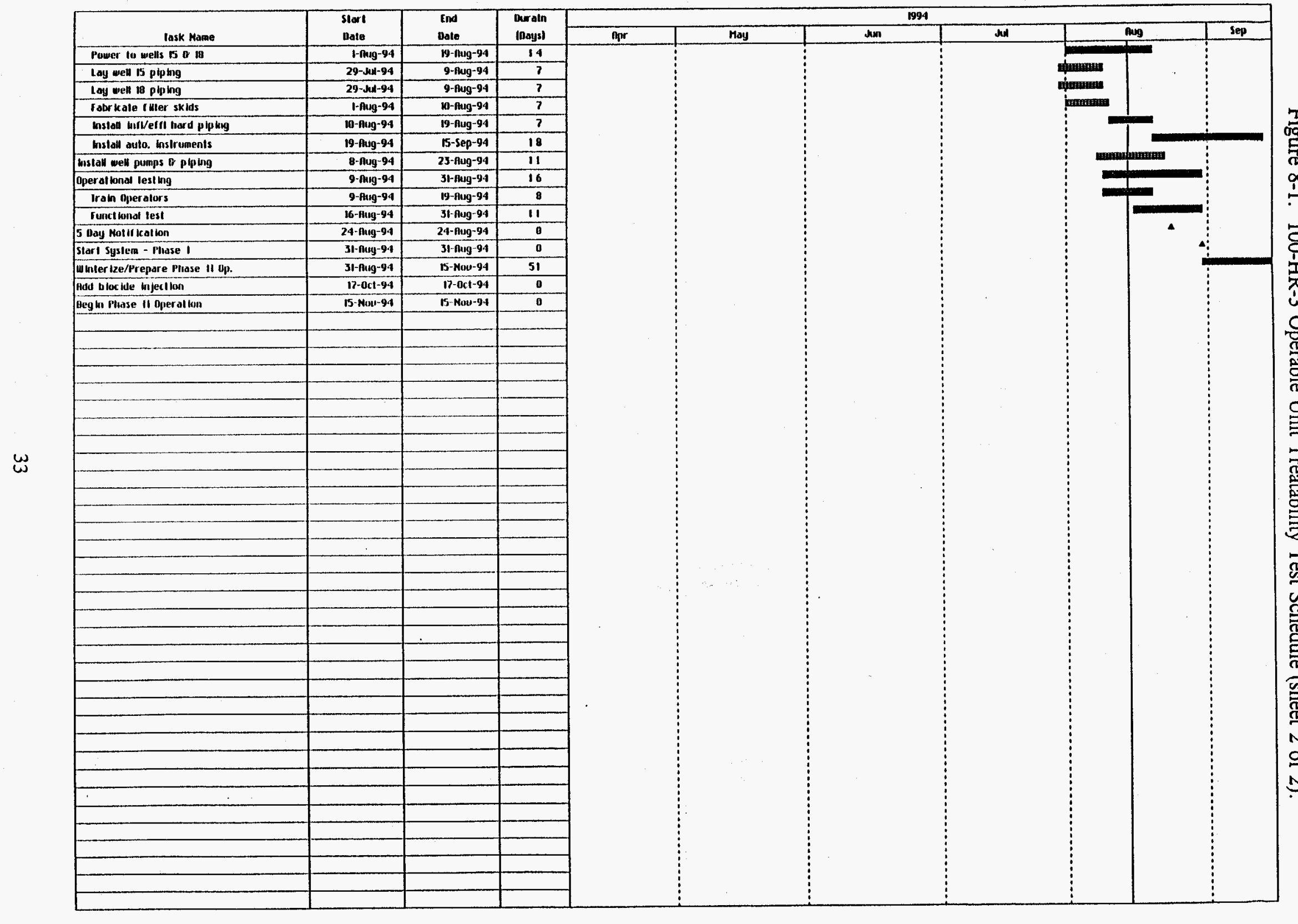

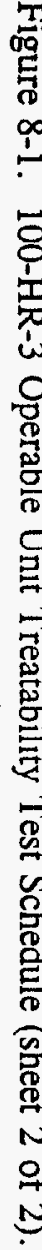

Localion of lest is nog-0 
Figure 9-1. 100-HR-3 Operable Unit Treatability Test Program Organization.

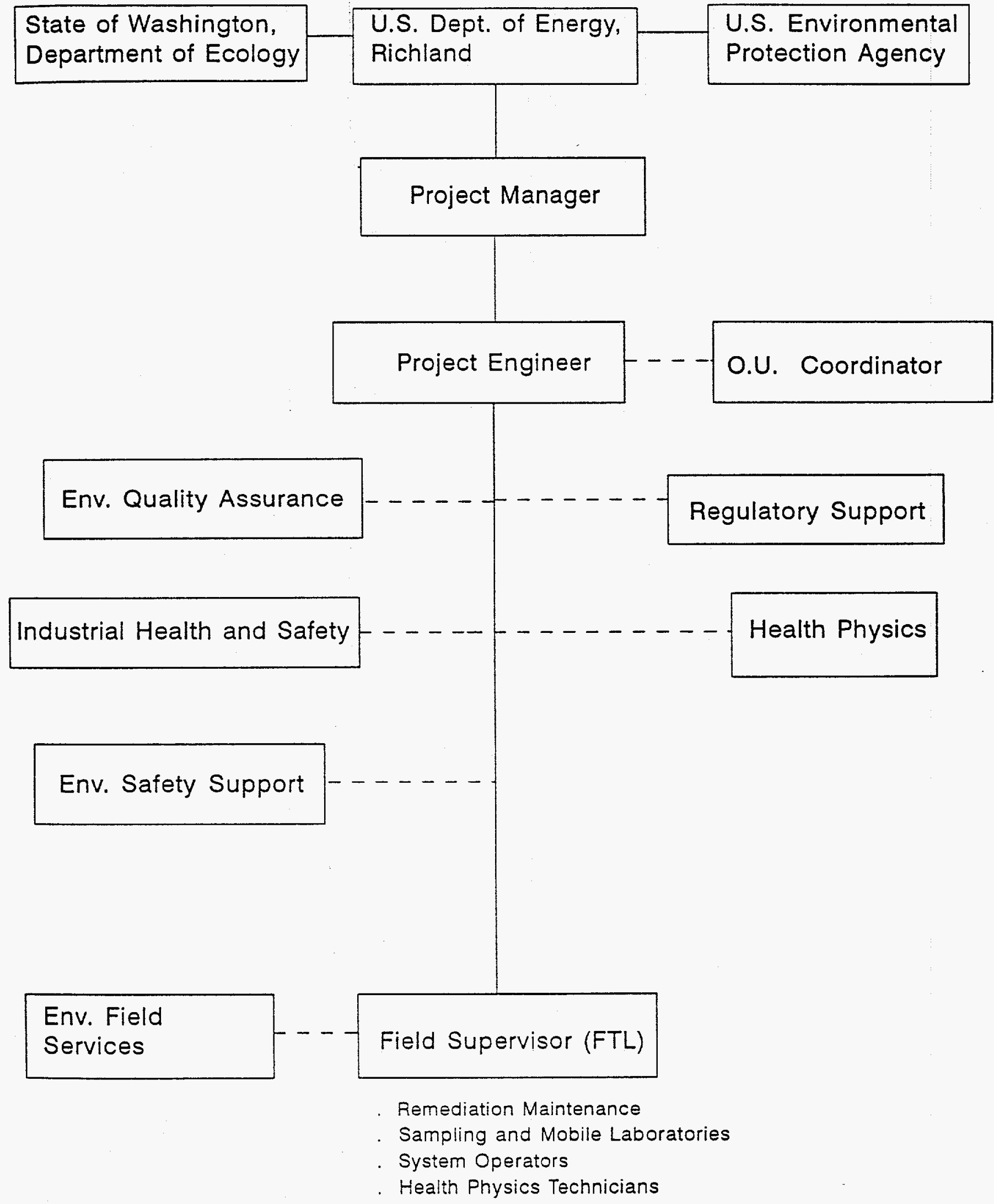


Table 9-1. Test Responsibilities.

\begin{tabular}{|c|c|}
\hline Organization & Responsibilities \\
\hline Environmental Engineering & $\begin{array}{l}\text { Provides Project Manager and Project Engineer for the Test. The project engineer } \\
\text { interfaces with regulators, DOE-RL and the OU coordinator to complete the test } \\
\text { plan/procedures and other field documentation prior to start-up of the test. The } \\
\text { projector engineer also works with the field supervisor to ensure the test is } \\
\text { conducted consistent with agreements and procedures. }\end{array}$ \\
\hline $\begin{array}{l}\text { Environmental Field Services/ } \\
\text { Health Physics (EFS/HP) }\end{array}$ & $\begin{array}{l}\text { Verifies worker health documentation meets requirements, provides HP technicians } \\
\text { support. Prepares radiation work permit. }\end{array}$ \\
\hline $\begin{array}{l}\text { Environmental Safety Quality } \\
\text { Assurance/Health, Safety, and Fire } \\
\text { Protection (ESQ/HSF) }\end{array}$ & $\begin{array}{l}\text { Inspects and approve seller's equipment for safety features. Review of safety } \\
\text { documentation. }\end{array}$ \\
\hline $\begin{array}{l}\text { Environmental Safety Project } \\
\text { Documentation }\end{array}$ & $\begin{array}{l}\text { Prepares safety analysis and ensures appropriate environmental safety and health } \\
\text { requirements are included in test plan and procedures. }\end{array}$ \\
\hline Regulatory Support & $\begin{array}{l}\text { Completes NEPA documentation, notifies state of air discharges, provides } \\
\text { regulatory support. }\end{array}$ \\
\hline Remediation Maintenance & $\begin{array}{l}\text { Excavates soils and feeds soil treatment systems, backfills excavated sites to pre- } \\
\text { test conditions. Sprays soils for dust control as needed. }\end{array}$ \\
\hline Site Remediation Management & $\begin{array}{l}\text { Provides field supervisor (FTL) for test who ensures that all field personnel are } \\
\text { trained, documentation is complete, and work is performed in accordance with } \\
\text { procedures. The FTL also coordinates all field activities. }\end{array}$ \\
\hline $\begin{array}{l}\text { Environmental Field Services/ Site } \\
\text { Safety (EFS/Site Safety) }\end{array}$ & $\begin{array}{l}\text { Completes hazardous waste operations plan for field activities and provides site } \\
\text { safety officer. }\end{array}$ \\
\hline $\begin{array}{l}\text { Environmiental Quality Assurance } \\
\text { (EQA) }\end{array}$ & $\begin{array}{l}\text { Oversees activities to ensure compliance with WHC and DOE QC requirements. } \\
\text { Ensures data generated from the test satisfies requirements of QA Plan. }\end{array}$ \\
\hline Equipment Testing Laboratory & $\begin{array}{l}\text { Design, testing, operation and maintenance of the equipment before and during the } \\
\text { test }\end{array}$ \\
\hline Sampling and Mobile Laboratory & Review sampling strategy and perform all required sampling. \\
\hline
\end{tabular}

DOE-RL U.S. Department of Energy, Richland Operations Office

EFS environmental field services

EQA environmental quality assurance

ESQ environmental safety and quality assurance

FTL field team leader

HP health physics

HSF health, safety, and fire protection

NEPA National Environmental Policy Act (1969)

OU operable unit

QA quality assurance

QC quality control

WHC Westinghouse Hanford Company 


\subsection{REFERENCES}

BHI, 1994, Waste Control Plan for the Pilot Scale Treatability Test for the 100-HR-3 Operable Unit, BHI-00021, Bechtel Hanford, Inc., Richland, Washington.

Cartwright, G. C., 1991, Limitations of Pump and Treat Technology, Pollution Engineering, November 1991, pp.64-68.

DOE/RL, 1988, 100-HR-3 Work Plan, DOE/RL-88-36, Rev. 0, U.S. Department of Energy, Richland Operations Office, Richland, Washington.

DOE/RL, 1990, RCRA Facility Investigation/Corrective Measures Study Work Plan for the 100-DR-1 Operable Unit, Hanford Site, Richland, Washington, DOE/RL 89-09, U. S. Department of Energy, Richland Operations Office, Richland, Washington.

DOE/RL, 1992a, RCRA Facility Investigation/Corrective Measures Study Work Plan for the 100-HR-3 Operable Unit, Hanford Site, Richland, Washington, DOE/RL-88-36, Draft C, U. S. Department of Energy, Richland Operations Office, Richland, Washington.

DOE/RL, 1992b, 100 Area Feasibility Study Phase 1 and 2, DOE/RL-92-11, Draft A, U. S. Department of Energy, Richland Operations Office, Richland, Washington.

DOE/RL, 1993, Limited Field Investigations Report for the 100-HR-3 Operable Unit, DOE/RL-93-43, Draft A, U. S. Department of Energy, Richland Operations Office, Richland, Washington.

Ecology, EPA, and DOE, 1989, et seq, Hanford Federal Facility Agreement and Consent Order, 2 Vols., Washington State Department of Ecology, U.S. Environmental Protection Agency, U.S. Department of Energy, Olympia, Washington.

Ecology, EPA, and DOE, 1994, et seq, Hanford Federal Facility Agreement and Consent Order, Fourth Amendment, Washington State Department of Ecology, U.S. Environmental Protection Agency, U.S. Department of Energy, Olympia, Washington.

EPA, 1986, Test methods for Evaluating Solid waste (SW-846), Third Edition, U. S. Environmental Protection Agency, Office of Solid Waste and Emergency response, Washington, D. C.

EPA, 1987, Data Quality Objectives for Remedial Response Activities Development Process, EPA/540-G-87/003 and 004, OSWER Directive 9335.3-01, U.S. Environmental Protection Agency, Washington, D.C.

EPA, 1989, Performance Evaluations of Pump-and-Treat Remediations, EPA/540/4-89/005, U.S. Environmental Protection Agency, Washington, D.C.

EPA, 1991, USEPA Contract Laboratory Program Statement of Work for Inorganics Analysis: MultiMedia Multi-Concentration, U. S. Environmental Protection Agency, Sample management laboratory, Washington, D. C. 
EPA, 1992, Guide for Conducting Treatability Studies under CERCLA, Final,

EPA/540/R-92/071a, U.S. Environmental Protection Agency, Washington, D.C.

Kopp, J.F., and G.D. McKee, 1983, Methods for Chemical Analysis of Water and Wastes, EPA/600/4-79-020, U.S. Environmental Protection Agency, Environmental Monitoring and Support Lab, Washington, D.C.

Krieger, H.L., and E.L. Whittaker, 1980, Prescribed Procedures for Measurement of Radioactivity in Drinking Water, EPA/600/480/0327, U.S. Environmental Protection Agency, Environmental Monitoring and Support Lab, Cincinnati, Ohio.

Lindahl, P.C., 1984, Determination of Inorganic Anions in Aqueous and Solid Samples of Ion Chromatography, EPA/600/4-84/017, Argonne National Laboratories, Argonne, Illinois.

WHC, 1987, Industrial Safety Manual, Vol. 1 through 3, WHC-CM-4-3, Westinghouse Hanford Company, Richland, Washington.

WHC, 1988a, Standard Engineering Practices, WHC-CM-6-1, Westinghouse Hanford Company, Richland, Washington.

WHC, 1988b, Environmental Investigation and Site Characterization Manual, WHC-CM-7-7, Westinghouse Hanford Company, Richland, Washington.

WHC, 1988c, Quality Assurance Manual, WHC-CM-4-2, Westinghouse Hanford Company, Richland, Washington.

WHC, 1988d, Health Physics Practices Manual, WHC-IP-0718, Westinghouse Hanford Company, Richland, Washington.

WHC, 1998e, Environmental Compliance Manual, WHC-CM-7-5; Westinghouse Hanford Company, Richland, Washington.

WHC, 1990, Environmental Engineering, Technology, and Permitting Function Quality Assurance Program Plan, WHC-EP-0383, Westinghouse Hanford Company, Richland, Washington.

WHC, 1992, Environmental Engineering and Geotechnology Function Procedures, WHC-CM-7-8, Vol. 4, Westinghouse Hanford Company, Richland, Washington.

WHC,1993a, Treatment Tests for Ex Situ Removal of Chromate, Nitrate, and Uranium (VI) from Hanford (100-HR-3) Groundwater Final Report, WHC-SD-ER-DTR-001, Rev. 0, Westinghouse Hanford Company, Richland, Washington.

WHC, 1993b, Westinghouse Radiological Control Manual, WHC-CM-1-6, Westinghouse Hanford Company, Richland, Washington. 
DOE/RL-94-54, Rev. 0

APPENDIX A

100-HR-3 OPERABLE UNIT

TREATABILITY TEST PROCESS SAMPLING AND ANALYSIS PLAN 


\subsection{INTRODUCTION}

This sampling and analysis plan (SAP) is for testing of an extraction, ion exchange (IX) and injection system in the 100-HR-3 Operable Unit. Monitoring wells D5-14, D5-15, and D5-16 will be used to extract groundwater, and wells D5-17, D5-18, and D5-19 will be used for reinjecting treated groundwater.

The test performance objectives and data quality objectives (DQO) for the test program are presented in Chapter 3.0 of the test plan. This appendix presents the process SAP to be followed for gathering data in support of these test performance objectives and DQOs. The primary focus of the test is to determine the overall process efficiency in removing chromium VI. Data obtained from the sampling effort may also provide useful information for optimizing the treatment process. All sampling activities must conform with the following:

- WHC-EP-0383, Environmental Engineering, Technology, and Permitting Function Quality Assurance Program Plan (WHC 1990)

- WHC-CM-1-6, Westinghouse Radiological Control Manual (WHC 1993)

- . WHC-CM 4-3, Industrial Safety Manual (WHC 1987)

- WHC-CM-7-5, Environmental Compliance Manual (WHC 1988a)

- WHC-CM-7-7, Environmental Investigations and Site Characterization Manual (WHC 1988b)

- WHC-CM-7-8, Volume 4, Environmental Engineering and Geotechnology Function Procedures (WHC 1992)

- $\quad$ Site-specific hazardous waste operations permit

- $\quad$ Site-specific radiation work permit

- $\quad$ Project-specific safety assessment.

WHC manuals (1988b and 1992) contain the specific sampling procedures to be followed during all process sampling activities. The Environmental Investigation and Site Characterization Manual (WHC 1988b) also provides specific procedures for sample packaging and shipping, chain of custody, and storage.

Field screening sampling results (Level I and II analyses) will be used for making real-time operational decisions. Field screening sampling activities have significantly fewer procedural requirements in comparison with the offsite laboratory analytical requirements. This allows for a relatively nonrestrictive sampling approach for operation of the equipment. Analytical level III and V analyses (excluding field screening methods for radionuclides), referred to as offsite laboratory analyses, will be used to confirm screening level analyses and to determine process removal efficiencies for chromium. 


\subsection{SAMPLE LOCATION/SCHEDULE}

Figure 4-1 of the main text shows the location of sampling points to monitor the IX influent and effluent streams.

Weekly confirmation samples of chromium VI will be collected from the combined influent line and from the lead-column effluent stream. These samples will be analyzed at an off-site laboratory and the results will be compared against daily field samples.

To provide a general understanding of which contaminants of concern (listed on the reduced analyte list in Table 3-1 of the main text) are removed by DOWEX $21 \mathrm{~K}^{\mathrm{TM}}$ resin (manufactured by Dow Chemical Co.) in the 100-HR-3 operating environment, two sampling iterations will be conducted. One will be at the first changeout of resin and the second will be at the second changeout. Each iteration will consist of three samples: a combined influent water stream, a leadcolumn effluent water stream, and a discharged resin sample.

Influent samples will be taken before effluent samples. The time interval between these two sets of samples will be similar to the residence time for water to flow between the two points. This will be done to minimize, as much as possible, variability in analytical results due to potential changes over time in the concentration of chromium VI in the influent stream.

In addition to weekly sampling, daily samples (or more frequent at the start of Phase I and Phase II test operations) will be collected from each well and the combined streams from all extraction wells and at the effluent port of the lead IX column. Field screening to control the treatment process will include monitoring for chromium VI using a Hach Kit, plus measurement of $\mathrm{pH}$ and temperature. Online instruments are being investigated and may be used for chromium VI screening analyses in Phase II testing.

All field screening analyses will be performed in accordance with the manufacturer's procedures. Offsite laboratory analyses will follow standard laboratory procedures.

Waste designation samples will be taken as required for disposal of spent resins and discarded filter cartridges. The sample analysis requirements for waste designation are documented in the WCP (BHI 1994). Results of these analyses will be recorded in the field log book.

\subsection{SAMPLE IDENTIFICATION}

Samples collected and submitted for laboratory analysis will be assigned identification numbers and tracked according to instructions found in Environmental Investigation Instruction (EII) 5.10 from the Environmental Investigations and Site Characterization Manual (WHC 1988b). Field screening samples will be assigned numbers as appropriate and will be recorded in the project field logbook. 


\subsection{SAMPLE HANDLING AND ANALYSIS}

Samples that are collected to be analyzed by an offsite laboratory will follow EII 5.1, from the Environmental Investigations and Site Characterization Manual (WHC 1988b). Samples that are collected to be analyzed via field screening methods will be analyzed at the site. Field screening results will be documented in the field logbook and will become part of the administrative record. Sample residue will be returned to the treatment process.

Offsite laboratory analytical data will be the primary source of information for determining process efficiencies. The analytical methods chosen must be able to detect total chromium and chromium VI reliably to concentrations $<50 \mathrm{ppb}$.

Primary analyses will be for chromium VI and total chromium. Samples will also be analyzed for constituents on the reduced analyte list (see Table 3-1 in the main text).

Groundwater samples from nearby wells will be taken during the ongoing bi-annual monitoring well sampling program. These samples will be analyzed for the reduced analytes list. Three sets of samples are required to be analyzed by December 1994.

Spent resin will be sampled for gross alpha and beta analyses and for Toxicity Characteristic Leaching Procedure (TCLP) analyses for waste designation purposes.

\subsection{QUALITY ASSURANCE/QUALITY CONTROL}

Data quality is controlled by the quality assurance project plan (QAPjP) presented in Appendix B. The quality assurance documents that cover the test activities are the Quality Assurance Manual (WHC 1988c) and the Environmental Engineering, Technology, and Permitting Function Quality Assurance Program Plan (WHC 1990).

Quality control (QC) sampling for Level III or V analyses will be performed in accordance with the procedures specified in this SAP and the QaPjP (Appendix B) and will be verified using duplicate and split samples. Quality assurance $(\mathrm{QA}) / \mathrm{QC}$ samples will be collected the following frequency:

- A minimum of one duplicate sample for every four offsite laboratory samples taken

- A minimum of one split sample for every four offsite laboratory samples taken.

Offline monitoring field screening data quality will be ensured by collecting and analyzing duplicate samples and by following the recommended calibration verification methods identified in the manufacturers procedures manual for the analyte in question. A minimum of one duplicate sample will be analyzed for every 20 samples taken.

Data obtained from online monitoring equipment will be controlled by adherence to the manufacturer's operating instructions. 
DOE/RL-94-54, Rev. 0

\subsection{REFERENCES}

BHI, 1994, Waste Control Plan for the Pilot-Scale Treatability Test for the 100-HR-3 Operable Unit, BHI-00021, Bechtel Hanford, Inc., Richland, Washington.

EPA, 1993; Protection of Environment, Title 40, Code of Federal Regulations, U.S. Environmental Protection Agency, Washington, D.C.

WHC, 1987, Industrial Safety Manual, Vol. 1 through 3, WHC-CM-4-3, Westinghouse Hanford Company, Richland, Washington.

WHC, 1988a, Environmental Compliance Manual, WHC-CM-7-5, Westinghouse Hanford Company, Richland, Washington.

WHC, 1988b, Environmental Investigations and Site Characterization Manual, WHC-CM-7-7, Volume I, Westinghouse Hanford Company, Richland, Washington.

WHC, 1988c, Quality Assurance Manual, WHC-CM-4-2, Westinghouse Hanford Company, Richland, Washington.

WHC, 1990, Environmental Engineering, Technology, and Permitting Function Quality Assurance Program Plan, WHC-EP-0383, Westinghouse Hanford Company, Richland, Washington.

WHC, 1992, Environmental Engineering and Geotechnology Function Procedures, WHC-CM-7-8, Vol. 4, Westinghouse Hanford Company, Richland, Washington.

WHC, 1993, Westinghouse Radiological Control Manual, WHC-CM-1-6, Westinghouse Hanford Company, Richland, Washington. 
DOE/RL-94-54, Rev. 0

APPENDIX B

100-HR-3 OPERABLE UNIT TREATABILITY TEST

QUALITY ASSURANCE PROJECT PLAN 


\section{GLOSSARY}

Accuracy: For the purposes of environmental investigations, accuracy may be interpreted as the measure of the bias in a system. Sampling accuracy is normally assessed through the evaluation of matrix-spikẹd samples, reference samples, and split samples.

Audit: For the purposes of environmental investigations, audits are considered to be systematic checks to verify the quality of operation of one or more elements of the total measurement system. In this sense, audits may be of two types: (1) performance audits, in which quantitative data are independently obtained for comparison with data routinely obtained in a measurement system, or (2) system audits, involving a qualitative onsite evaluation of laboratories or other organizational elements of the measurement system for compliance with established quality assurance program and procedure requirements. For environmental investigations at the Hanford Site, performance audit requirements are fulfilled by periodic submittal of blind samples to the primary laboratory, or the analysis of split samples by an independent laboratory. System audit requirements are implemented through the use of standard surveillance procedures.

Bias: Bias represents a systematic error that contributes to the difference between a population mean of a set of measurements and an accepted reference or true value.

Blind Sample: A blind sample refers to any type of sample routed to the primary laboratory for performance audit purposes, relative to a particular sample matrix and analytical method. Blind samples are not specifically identified as such to the laboratory. They may be made from traceable standards or may consist of sample material spiked with a known concentration of a known compound. See the glossary entry for Audit.

Comparability: For the purposes of environmental investigations, comparability is an expression of the relative confidence with which one data set may be compared with another.

Completeness: For the purposes of environmental investigations, completeness may be interpreted as a measure of the amount of valid data obtained compared to the total data expected under correct normal conditions.

Deviation: For the purposes of environmental investigations, deviation refers to an approved departure from established criteria that may be required as a result of unforeseen field situations or that may be required to correct ambiguities in procedures that may arise in practical applications.

Equipment Blanks: Equipment blanks consist of pure deionized, distilled water washed through decontaminated sampling equipment and placed in containers identical to those used for actual field samples. They are used to verify the adequacy of sampling equipment decontamination procedures and are normally collected at the same frequency as field duplicate samples.

Field Blanks: Field blanks for water analyses consist of pure deionized, distilled water, transferred to a sample container at the site and preserved with the reagent specified for the analytes of interest. They are used to check for possible contamination originating with the reagent or the sampling environment and are normally collected at the same frequency as field duplicate samples. 
Field Duplicate Sample: Field duplicate samples are samples retrieved from the same sampling location using the same equipment and sampling technique, placed in separate, identically prepared and preserved containers, and analyzed independently. Field duplicate samples are generally used to verify the repeatability or reproducibility of analytical data and are normally analyzed with each analytical batch or every 20 samples, whichever is greater.

Matrix-Spiked Samples: Matrix-spiked samples are a type of laboratory quality control sample. They are prepared by splitting a sample received from the field into two homogenous aliquots (i.e., replicate samples) and adding a known quantity of a representative analyte of interest to one aliquot in order to calculate the percentage of recovery of that analyte.

Nonconformance: A nonconformance is a deficiency in the characteristic, documentation, or procedure that renders the quality of material, equipment, services, or activities unacceptable or indeterminate. When the deficiency is of a minor nature, does not effect a permanent or significant change in quality if it is not corrected, and can be brought into conformance with immediate corrective action, it shall not be categorized as a nonconformance. If the nature of the condition is such that it cannot be immediately and satisfactorily corrected, however, it shall be documented in compliance with approved procedures and brought to the attention of management for disposition and appropriate corrective action.

Precision: Precision is a measure of the repeatability or reproducibility of specific measurements under a given set of conditions. The relative percent difference (RPD) is used to assess the precision of the sampling and analytical method. The RPD is a quantitative measure of the variability. Specifically, precision is a quantitative measure of the variability of a group of measurements compared to their average value. Precision is normally expressed in terms of standard deviation but may also be expressed as the coefficient of variation (i.e., relative standard deviation) and range (i.e., maximum value minus minimum value). Precision is assessed by means of duplicate/replicate sample analysis.

Quality Assurance: For the purposes of environmental investigations, quality assurance refers to the total integrated quality planning, quality control, quality assessment, and corrective action activities that collectively ensure that the data from monitoring and analysis meet all end user requirements and/or the intended end use of the data.

Quality Assurance Project Plan: The quality assurance project plan is an orderly assembly of management policies, project objectives, methods, and procedures that defines how data of known quality will be produced for a particular project or investigation.

Quality Control: For the purposes of environmental investigations, quality control refers to the routine application of procedures and defined methods to the performance of sampling, measurement, and analytical processes.

Range: Range refers to the difference between the largest and smallest reported values in a sample and is a statistic for describing the spread in a set of data.

Reference Samples: Reference samples are a type of laboratory quality control sample prepared from an independent, traceable standard at a concentration other than that used for analytical equipment calibration, but within the calibration range. Such reference samples are required for every analytical batch or every 20 samples, whichever is greater. 
Replicate Sample: Replicate samples are two aliquots removed from the same sample container in the laboratory and analyzed independently.

Representativeness: For the purposes of environmental investigations, representativeness may be interpreted as the degree to which data accurately and precisely represent a characteristic of a population parameter, variations at a sampling point, or an environmental condition.

Representativeness is a qualitative parameter that is most concerned with the proper design of a sampling program.

Split Sample: A split sample is produced through homogenizing a field sample and separating the sample material into two equal aliquots. Field split samples are usually routed to separate laboratories for independent analysis, generally for purposes of auditing the performance of the primary laboratory relative to a particular sample matrix and analytical method. See the glossary entry for Audit. In the laboratory, samples are generally split to create matrix-spiked samples (see the glossary entry).

Verification: For the purposes of environmental investigations, verification refers to the process of determining whether procedures, processes, data, or documentation conform to specified requirements. Verification activities may include inspections, audits, surveillance, or technical review. 
DOE/RL-94-54, Rev. 0

B-iv 
DOE/RL-94-54, Rev. 0

\section{ACRONYMS}

$\begin{array}{ll}\text { CLP } & \text { Contract Laboratory Program } \\ \text { CRDL } & \text { Contract Required Detection Limit } \\ \text { DOE/RL } & \text { U.S. Department of Energy, Richland Operations Office } \\ \text { DQO } & \text { data quality objective } \\ \text { EII } & \text { Environmental Investigation Instruction } \\ \text { EPA } & \text { U.S. Environmental Protection Agency } \\ \text { FTL } & \text { field team leader } \\ \text { HEIS } & \text { Hanford Environmental Information System } \\ \text { QA } & \text { quality assurance } \\ \text { QAPI } & \text { Quality Assurance Program Index } \\ \text { QAPjP } & \text { quality assurance project plan } \\ \text { QC } & \text { quality control } \\ \text { QI } & \text { Quality Instruction } \\ \text { QR } & \text { Quality Requirement } \\ \text { SAP } & \text { sampling and analysis plan } \\ \text { SOW } & \text { Statement of Work } \\ \text { WHC } & \text { Westinghouse Hanford Company }\end{array}$


DOE/RL-94-54, Rev. 0 


\subsection{INTRODUCTION}

This quality assurance project plan (QAPjP) supports data collection activities associated with pilot-scale testing described in the 100-HR-3 Operable Unit treatability test plan. Project activities will consist of testing of an extraction, ion exchange, and injection system. The test activities include groundwater and process monitoring as described in the sampling and analysis plan (SAP) (Appendix A of the test plan).

This QAPjP was prepared in compliance with the requirements of WHC-EP-0383, Environmental Engineering, Technology, and Permitting Function Quality Assurance Program Plan (WHC 1990a). WHC-EP-0383 describes the means selected to implement the overall quality assurance (QA) program requirements defined by the Westinghouse Hanford Company (WHC) WHC-CM-4-2, Quality Assurance Manual (WHC 1988a), as applicable to environmental investigations, while accommodating the specific requirements for project plan format and content agreed upon in the Hanford Federal Facility Agreement and Consent Order (Ecology et al. 1989). Distribution and revision control of the treatability test plan and the QAPjP will be in compliance with Quality Requirement (QR) QR 6.0, "Document Control" (WHC 1988a) and other applicable procedures as identified in the QA Program Index (QAPI) included in WHC-EP-0383 (WHC 1990a).

Interim changes to this QAPjP or the treatability test plan shall be documented, reviewed, and approved as required by Section 6.6 of Environmental Investigation Instruction (EII) 1.9, "Primary and Secondary Document Review and Control" (WHC 1988b), and shall be documented in monthly unit managers' meeting minutes. All plans and procedures referenced in the QAPjP are available upon request of the WHC technical project lead.

\subsection{PROJECT ORGANIZATION AND RESPONSIBILITIES}

The following sections identify responsibilities of project personnel. The overall organization for the pilot-scale testing is provided in Chapter 9.0 of the treatability test plan. Responsibility descriptions and individual field team descriptions are addressed in the governing project procedures identified in Chapter 4.0 of this QAPJP.

\subsection{TECHNICAL LEAD RESPONSIBILITIES}

The Hanford Environmental Restoration Contractor will have primary responsibilities for conducting this investigation. During transition from WHC to the Environmental Restoration Contractor, all activities will be conducted in accordance with previously approved WHC procedures. The project manager will be responsible for this test.

The Project Engineer will interface with regulators, U.S. Department of Energy, Richland Operations Office (DOE/RL), and the operable unit coordinator to complete the test plan/procedures and other field documentation prior to start-up of the test. The project engineer will also work with the field supervisor to ensure the test is conducted consistent with agreements and procedures. 
The project supervisor or field team leader (FTL) will be responsible for all test related activities in the field. The FTL ensures all field personnel are trained, documentation is complete, and work is performed in accordance with procedures. The FTL also coordinates all field activities.

External participant contractors or subcontractors will be evaluated and selected for certain portions of task activities at the direction of the project engineer in compliance with procedures QR 4.0, "Procurement Document Control," QR 7.0, "Control of Purchased Items and Services" (WHC 1988a), and other procedures as identified under criteria four and seven of the QAPI included in WHC-EP-0383 (WHC 1990a). All contractor or subcontractor plans and procedures shall be approved before their use and shall be available for regulatory review after WHC approval.

\subsection{QUALITY ASSURANCE OFFICER RESPONSIBILITIES}

The QA Officer (i.e., the Cognizant QA Manager) is responsible for coordination and/or oversight of performance to the QAPjP requirements by means of internal auditing and surveillance techniques. The QA Officer has the necessary organizational independence and authority to identify conditions adverse to quality and to inform the project engineer of needed corrective action.

\subsection{ANALYTICAL LABORATORIES}

Nonradioactive samples may be sent to any approved participant contractor or subcontractor analytical laboratory.

Offsite analyses shall be performed in compliance with WHC-approved laboratory QA plans and analytical procedures. Analytical laboratories shall be subject to the surveillance controls described by Quality Instruction (QI) 10.4, "Surveillance" (WHC 1988a). For subcontractors or participant contractors, applicable quality requirements shall be invoked as part of the approved procurement documentation or work order (Section 3.0 and 4.1.2 of this QAPjP). The laboratory shall submit its QA plan and applicable analytical procedures for WHC approval prior to their use, as noted in Section 4.1.2 of this QAPJP.

The WHC field sampling team will be responsible for screening all spent resin samples for radioactivity in compliance with WHC-CM-4-10, Radiation Protection Manual (WHC 1988c).

Spent resin samples sent offsite shall be packaged and shipped in compliance with Section 6.3 of EII 5.11, "Sample Packaging and Shipping" (WHC 1988b). If the total activity of a sample is equal to or greater than $200 \mathrm{pCi} / \mathrm{g}$, or if the alpha activity of the sample is equal to or greater than $60 \mathrm{pCi} / \mathrm{g}$, the sample will be routed to a WHC or Hanford Site participant contractor or subcontractor laboratory equipped and qualified to handle the analysis of radioactive samples.

\subsection{OTHER SUPPORT CONTRACTORS}

Procurement of all other field services and supporting items, materials, or equipment shall comply with standard WHC procurement procedures as discussed in Sections 2.1 and 4.1 of this QAPjP. All work shall comply with WHC-approved QA plans and/or procedures and is subject to the controls of QI 10.4, "Surveillance" (WHC 1988a). Applicable QRs shall be invoked as part of 
the approved procurement documentation or work order as noted in Section 4.1 of this QAPjP.

\subsection{QUALITY ASSURANCE OBJECTIVES FOR MEASUREMENTS}

Data quality objectives (DQOs) and data needs for this investigation are presented in Section 3.0 of the test plan.

Where EPA Contract Laboratory Program (CLP) methods are specified, the Contract Required Detection Limits (CRDLs) for inorganic parameters and the maximum precision and accuracy ranges specified by the appropriate CLP Statements of Work (SOWs) (EPA 1991a, EPA 1991b) apply. For non-CLP parameters, precision and accuracy ranges are provided that shall be considered maximum values that can be reliably achieved by analytical laboratories under routine conditions.

The requirements for primary and reduced analyte constituents shown in Table 3-1 of the text shall be considered a minimum performance standard for characterizing groundwater and solids, and shall be incorporated into the agreements for services established with individual WHC, participant contractor, or subcontractor analytical laboratories. Modification of Table 3-1 (in the main text) requirements is subject to regulatory review and approval.

Goals for data representativeness will be addressed qualitatively by the specification of sampling locations and frequencies, as previously described in the SAP (Appendix A). Sampling practices will be specified in operating procedures and work orders issued to the subcontractors or participating contractors responsible for conducting sampling activities. Precision and accuracy shall be met for at least $90 \%$ of the total number of samples analyzed.

\subsection{SAMPLE PROCEDURES}

\subsection{PROCEDURE APPROVALS AND CONTROL}

The WHC procedures cited in this QAPjP are consistent with WHC-EP-0383 (WHC 1990a). Procedure approval, revision, and distribution control requirements are addressed in EII 1.2, "Preparation and Revision of Environmental Investigations Instructions" (WHC 1988b). Requirements applicable to QIs and QRs are addressed in QR 5.0, "Instructions, Procedures, and Drawings" (WHC 1988a).

As noted in Section 2.0, participant contractor and/or subcontractor services shall be procured under the applicable requirements of QR 4.0, "Procurement Document Control," QR 7.0, "Control of Purchased Items and Services" (WHC 1988a), and other procedures as identified under criteria four and seven of the QAPI (WHC 1990a). Contractor procedures shall be reviewed and approved by WHC, or where possible, contractors shall work to WHC procedures. 
Analytical laboratories shall be required to submit a QA program plan, in addition to analytical procedures. All analytical laboratory plans and procedures shall be reviewed and approved by qualified personnel from the WHC Analytical Laboratories organization, or other qualified personnel, as directed by the technical lead. Reviewers shall be qualified under the requirements of EII 1.7, "Indoctrination, Training, and Qualification" (WHC 1988b).

Contractor or subcontractor procedures, plans, and/or manuals shall be retained as project records in compliance with Section 2 of WHC-CM-3-5, Document Control and Records Management Manual (WHC 1990b). All such documents are available to the regulators upon request.

\subsection{SAMPLING PROCEDURES}

Sample acquisition procedures are described in the SAP for process monitoring (Appendix A of the test plan). The waste control plan can be found in BHI (1994).

Sample container types, preservation requirements, preparation requirements, and special handling requirements are defined in EII 5.8, "Groundwater Sampling" and EII 5.11, "Sample Packaging and Shipping" (WHC 1988b).

\subsection{PROCEDURE CHANGES}

Deviations from EIIs may be authorized by the FTL in accordance with the requirements specified in EII 1.5, "Instruction Change Authorizations" (WHC 1988b). Documentation, review, and disposition of instruction change authorization forms shall be in accordance with EII 1.4 (WHC 1988b). Other types of procedure change requests shall be documented as required by QR 6.0, "Document. Control" (WHC 1988a) and WHC-EP-0383 (WHC 1990a).

\subsection{SAMPLE CUSTODY}

All samples obtained during the course of this investigation shall be controlled per EII 5.1, "Chain of Custody" (WHC 1988b). Laboratory chain-of-custody procedures shall be reviewed and approved in compliance with the requirements of Section 4.1 of this QAPjP, and shall ensure the maintenance of sample integrity and identification throughout the analytical process. Chain-of-custody forms shall be initiated for returned residual samples. All analytical results shall be controlled as permanent project quality records per Section 9 of WHC-CM-3-5 (WHC 1990b).

\subsection{CALIBRATION PROCEDURES}

Calibration of WHC M\&TE shall be in accordance with manufacturer's specifications. Calibration requirements for analytical laboratories shall be subject to WHC review and approval and shall meet QR 12.0 (WHC 1988a). 


\subsection{DATA REDUCTION AND REPORTING}

\subsection{DATA REDUCTION AND DATA PACKAGE PREPARATION}

Analytical laboratories shall prepare a report summarizing the results of analysis and a detailed data package that includes identifying samples, sampling and analysis dates, raw analytical data, reduced data, data outliers, reduction formulas, recovery percentages, quality control (QC) check data, equipment calibration data, supporting chromatogram or spectrograms, and documentation of any nonconformances affecting the measurement system in use during the analysis of the particular group of samples.

Data reduction schemes shall be contained within individual laboratory analytical methods and/or QA manuals, submitted for WHC review and approval as discussed in Section 4.1 of this QAPjP. The completed data package shall be reviewed and approved by the analytical laboratory's QA manager (or FTL for field screening type analysis) before being submitted to the WHC project engineer.

No validation will be required since only interim action decisions are being supported.

\subsection{FINAL REVIEW AND RECORDS MANAGEMENT CONSIDERATIONS}

All supporting analytical data packages shall be reviewed by a qualified reviewer before being submitted to regulatory agencies, prior to entry into the Hanford Environmental Information System (HEIS) (EII 14.1, "Analytical Laboratory Data Management" [WHC 1988b]), or before inclusion in reports or technical memoranda. All verification and validation reports, data packages, and review comments shall be retained as permanent project quality records in compliance with Section 9 of WHC-CM-3-5 (WHC 1990b).

\subsection{INTERNAL QUALITY CONTROL}

Unless otherwise specified in the approved SOWs or work orders for sampling activities, or in applicable EIIs, the following minimum field QC requirements apply. These requirements are adapted from Test Methods for Evaluating Solid Waste (EPA 1986), as modified by the proposed rule changes included in the Federal Register, 1989, Volume 54, No. 13, pp 3212-3228, and 1990, Volume 55, No. 27, pp 4440-4445.

- Field duplicate samples. Duplicate samples shall be obtained from the same sampling location using the same equipment and sampling technique and shall be placed into two identically prepared and preserved containers. All field duplicates shall be analyzed independently to assess the magnitude of field variability and the need for more duplicates. One duplicate sample shall be collected for every 4 samples taken.

- $\quad$ Split samples. Upon specific WHC or regulator request, and at the direction of the FTL, field duplicate samples may be split in the field and sent to an alternate 
laboratory as a performance audit of the primary laboratory.

- $\quad$ Blind samples. At the technical lead's discretion, blind reference samples may be introduced into any sampling round as a QC check of the primary laboratory. Blind sample type shall be as directed by the technical lead.

- $\quad$ Field blanks. Field blanks shall consist of pure deionized distilled water transferred into a sample container at the site and preserved with the reagent specified for the analytes of interest. Field blanks are used as a check on reagent and environmental contamination and shall be collected at the same frequency as field duplicate samples.

- $\quad$ Equipment rinsate blanks. Equipment blanks shall consist of pure deionized distilled water washed through decontaminated sampling equipment and placed in containers identical to those used for actual field samples. Equipment blanks are used to verify the adequacy of sampling equipment decontamination procedures and shall be collected at the same frequency as field duplicate samples where applicable.

Unless otherwise specified in WHC-approved analytical methods, internal QC checks performed by analytical laboratories shall meet the following minimum requirements.

- $\quad$ Matrix-spike/matrix-spike duplicate samples. In matrix-spiked samples a known quantity of a representative analyte of interest is added to the sample to measure analytical recovery percentage and analytical precision. The spike shall be a replicate of a field duplicate sample. Replicate samples are separate aliquots removed from the sample container in the laboratory. Spike compound selection, quantities, and concentrations shall be described in the analytical procedures submitted for WHC review and approval. One sample shall be spiked per analytical batch, or once every four samples, whichever is more frequent.

- Quality control reference samples. A QC reference sample shall be prepared from an independent standard at a concentration other than that used for calibration, but within the calibration range. Reference samples are required as an independent check on analytical technique and methodology and shall be run with every analytical batch, or every 20 samples, whichever is more frequent.

Duplicates shall be selected, whenever possible, from samples in which significant readings have been observed during field analysis.

\subsection{PERFORMANCE AND SYSTEM AUDITS}

Performance, system, and program audits will begin early in the execution of the pilot-scale test program and continue through completion. The audits address quality-affecting activities including measurement system accuracy, intramural and extramural analytical laboratory services, field activities, and data collection, processing, and management. 
Performance audits of the accuracy of laboratory analysis are implemented in accordance with Standard Operating Procedure EII 1.12 "Laboratory Analysis Performance Audits" (WHC 1988b). System audit requirements are implemented in accordance with Standard Operating Procedure requirements of WHC-CM-4-2 (WHC 1988a). Surveillances will be performed regularly throughout the course of the work plan activities. Additional performance and system "surveillances" may be scheduled as a consequence of corrective action requirements or may be performed upon request. All quality-affecting activities are subject to surveillance.

All aspects of inter-operable unit activities will also be evaluated as part of routine environmental restoration program-wide QA audits under the Standard Operating Procedure requirements of WHC-CM-4-2 (WHC 1988a). Program audits shall be conducted in accordance with QR 18.0, "Audits," QI 18.1, "Audit Programming and Scheduling," and QI 18.2, "Planning, Performing, Reporting, and Follow-up of Quality Audits" (WHC 1988a) by auditors qualified in accordance with QI 2.5, "Qualification of Quality Assurance Personnel" (WHC 1988a).

\subsection{PREVENTIVE MAINTENANCE}

Preventive maintenance measures shall be used to ensure minimum downtime and corresponding schedule delays for measurement and testing equipment used in the field and laboratories. Laboratories shall be responsible for maintaining analytical equipment. Maintenance requirements, spare parts lists, and instructions shall be included in individual laboratory QA plans, subject to WHC review and approval as noted in Sections 2.1, 2.2, and 4.1 of this QAPJP.

When samples are analyzed using U.S. Environmental Protection Agency (EPA) reference methods, the preventive maintenance requirements for laboratory analytical equipment are as defined in the procured laboratory's QA plan(s). The WHC field equipment shall be drawn from inventories with standard preventive maintenance and calibration procedures (criterion 12 of the QAPI [WHC 1990a]). Field procedures submitted for WHC approval by participant contractors or subcontractors shall contain, as appropriate, provisions for preventive maintenance schedules and spare parts lists to minimize equipment downtime.

\subsection{DATA ASSESSMENT PROCEDURES}

Analytical data shall be compiled, reduced, and reviewed by the laboratory. Depending on the distribution and statistical characteristics of the data and other unit- or area-specific considerations, various statistical and/or probabilistic techniques may be selected for use in the process of data comparison or analysis. The selection of any such methodology shall be approved and authorized by the project engineer. Methods shall be documented, signed, dated, and retained as project records in compliance with Section 2 of WHC-CM-3-5 (WHC 1990b). 
DOE/RL-94-54, Rev. 0

\subsection{CORRECTIVE ACTION}

\subsection{GENERAL REQUIREMENTS FOR CORRECTIVE ACTION}

Corrective action requests required as a result of surveillance reports, nonconformance reports, program audit activities, or at the request of the operable unit manager shall be documented and dispositioned by the project engineer and QA coordinator (QR 16.0, "Corrective Action" [WHC 1988a]). Corrective action reports prepared under QR 16.0 requirements shall identify the affected requirement, the probable cause of the deviation, any data that may have been affected by the deviation, and the corrective action required both to resolve the immediate situation and to reduce or preclude its recurrence.

Correction of plans or procedures related to the measurement system that do not constitute nonconformances, but which may be required as a result of data assessment or routine review processes, shall be resolved as required by their governing procedures or shall be referred to the project engineer for resolution and appropriate management action. All documentation related to surveillances, audits, and corrective action shall be maintained in compliance with EII 1.6, "Records Processing". (WHC 1988b) and routed to the project quality records upon completion or closure for retention in compliance with Section 9 of WHC-CM-3-5 (WHC 1990b). It shall also be made available for operable unit manager review upon request through the project engineer or operable unit coordinator.

\subsection{CORRECTIVE ACTION REQUIREMENTS RELATED TO CALIBRATION ERRORS}

Field M\&TE found to be out of calibration shall be documented as a nonconformance item (QR 15.0, "Control of Nonconforming Items". [WHC 1988a]). Nonconforming items shall be tagged, removed from service, and segregated pending resolution of the nonconformance and initiation of appropriate corrective action.

Calibration errors shall result in requests for reanalysis or other appropriate corrective action by the responsible laboratory. If sample holding time requirements are compromised, insufficient sample material is available for reanalysis, or any other condition prevents compliance with governing analytical methods, the project engineer and QA Coordinator shall be informed and shall take appropriate action (QR 16) (WHC 1988a).

\subsection{CORRECTIVE ACTION REQUIREMENTS RELATED TO PROCEDURAL DEVIATIONS}

Planned deviations from EII requirements shall be approved and documented per EII 1.4, "Instruction Change Authorization" (WHC 1988b). Unplanned procedural deviations observed during system audit, surveillance, or program audit activities shall be documented as nonconformances, findings, or observations in compliance with the procedures described in Section 12.0. Corrective action shall be initiated as noted in Section 13.1. 


\subsection{CORRECTIVE ACTION REQUIREMENTS RELATED TO PURCHASED MATERIALS, ITEMS, OR EQUIPMENT}

Purchased materials, items, and equipment found to be out of compliance with procurement specifications shall be documented as a nonconformance item (QR 15.0, "Control of Nonconforming Items" [WHC 1988a]). Nonconforming items shall be tagged and segregated pending resolution of the nonconformance and initiation of appropriate corrective action in compliance with QR 16.0, "Corrective Action" (WHC 1988a).

\subsection{QUALITY ASSURANCE REPORTS}

Surveillance, nonconformance, audit and corrective action documentation shall be routed to the project quality records on completion or closure of the activity. A report summarizing corrective action shall be prepared for the project engineer by QA at the completion of the field and laboratory investigations. Such information will become an integral part of the test report to be prepared at the completion of testing (Chapter 9.0 of the 100-HR-3 treatability test plan). The test report shall include an assessment of the adequacy of the measurement system with regard to the DQOs of the investigation.

\subsection{REFERENCES}

BHI, 1994, Waste Control Plan for the Pilot-Scale Treatability Test for the 100-HR-3 Operable Unit, BHI-00021, Bechtel Hanford, Inc., Richland, Washington.

Ecology, EPA, and DOE, 1989, et seq, Hanford Federal Facility Agreement and Consent Order, 2 Vols., Washington State Department of Ecology, U.S. Environmental Protection Agency, U.S. Department of Energy, Olympia, Washington.

EPA, 1986, Test Methods for Evaluating Solid Waste (SW-846), Third Edition, U.S. Environmental Protection Agency, Office of Solid Waste and Emergency Response, Washington, D.C.

EPA, 1991a, USEPA Contract Laboratory Program Statement of Work for Inorganics Analysis: Multi-Media Multi-Concentration, U.S. Environmental Protection Agency, Sample Management Laboratory, Washington, D.C.

EPA, 1991b, USEPA Contractor Laboratory Program Statement of Work for Organics Analysis: Multi-Media, Multi-Concentration, U.S. Environmental Protection Agency, Sample Management Laboratory, Washington, D.C.

WHC, 1988a, Quality Assurance Manual, WHC-CM-4-2, Westinghouse Hanford Company, Richland, Washington. 
WHC, 1988b, Environmental Investigations and Site Characterization Manual, WHC-CM-7-7, Westinghouse Hanford Company, Richland, Washington.

WHC, 1988c, Radiation Protection Manual, WHC-CM-4-10, Westinghouse Hanford Company, Richland, Washington.

WHC, 1990a, Environmental Engineering, Technology, and Permitting Function Quality Assurance Program Plan, WHC-EP-0383, Westinghouse Hanford Company, Richland, Washington.

WHC, 1990b, Document Control and Records Management Manual, WHC-CM-3-5, Westinghouse Hanford Company, Richland, Washington.

\subsection{BIBLIOGRAPHY}

Kopp, J.F., and G.D. McKee, 1983, Methods for Chemical Analysis of Water and Wastes, EPA-600/4-79-020, U.S. Environmental Protection Agency, Environmental Monitoring and Support Laboratory, Washington, D.C.

Krieger, H.L., and E.L. Whittaker, 1980, Prescribed Procedures for Measurement of Radioactivity in Drinking Water, EPA/600/4-80/032, U.S. Environmental Protection Agency, Environmental Monitoring and Support Laboratory, Cincinnati, Ohio.

WHC, 1990, Sample Management and Administration Manual, WHC-CM-5-3, Westinghouse Hanford Company, Richland, Washington.

WHC, 1990, Hanford Environmental Information System (HEIS) User's Manual, WHC-EP-0372, Westinghouse Hanford Company, Richland, Washington. 
DOE/RL-94-54, Rev. 0

APPENDIX C

EQUIPMENT SPECIFICATIONS 
The following specifications were sent to the vendor for the Ion Exchange Unit.

The vendor shall provide an ion exchange unit that has the following characteristics:

- $\quad$ skid-mounted four-column unit with plumbing to use three columns with one in reserve and backwash/replace resin in one while still maintaining three columns

- modular design for possible future capacity increases

- $\quad$ electric service will be 480 Volt, 3 -phase, vendor to provide the power requirements

- $\quad$ rated for a 50 -gal/min flow rate

- all pumps, plumbing, and appurtances associated with a downflow backwashable ion exchange bed

- $\quad$ ports for ease of resin removal/replacement

- $\quad$ remote process control via personal computer modem

- column, etc. to contain 16 - 30 Mesh DOWEX $21 \mathrm{~K}^{\mathrm{TM}}$ resin (to be purchased by buyer) and be compatible with DOWEX $21 \mathrm{~K}$ specifications (the following was extracted from DOW project literature entitled: "Uranium Recovery with DOWEX Ion Exchange Resin, DOW Chemical, Separations and Process Systems Department, 1-800-256-2436."

- Screen Size Specifications

Through 16 Mesh on 30 Mesh (1.190 microns to 590 microns) Through 30 Mesh (590 microns)
$95 \%$ minimum

$3 \%$ maximum

- Pressure drop vs. flow rate at $50 \mathrm{gal} / \mathrm{min}$, chloride form, is approximately $4.3 \mathrm{psi} / \mathrm{ft}$ resin

- Suggested operating conditions:

pH Range

Maximum temperature chloride form Minimum bed depth

Regenerant flow rate

Regenerant temperature Rinse water requirements Displacement rinse rate
$0-14$

$100^{\circ} \mathrm{C}$

2 - $4 \mathrm{gal} / \mathrm{min} / \mathrm{ft}^{3}$ (16 to 32 Bed Volumes $/ \mathrm{h}$ )

$0.25-1.0 \mathrm{gal} / \mathrm{min} / \mathrm{ft}^{3}$ (2.0 to $8.0 \mathrm{Bed}$ Volumes/h)

Ambient

Approximately $50 \mathrm{gal} / \mathrm{ft}^{3}$

Sufficient to produce at least $50 \%$ Expansion in Bed Volume 


\section{DOE/RL-94-54, Rev. 0}

- Typical DOWEX $21 \mathrm{~K}^{\mathrm{TM}}$ Resin Properties

Physical Form

Sphericity

Total exchange capacity

Water retention capacity

Color throw, APHA no.

Classified density
Hard golden-brown-colored spheres $90 \%$ whole bead (minimum)

$1.2 \mathrm{meq} / \mathrm{mL}$ (minimum)

$50-58 \%$

20 (maximum)

$43 \mathrm{lb} / \mathrm{ft}^{3}$ 
DOE/RL-94-54, Rev. 0

\section{DISTRIBUTION}

Number of Copies

\section{Onsite}

21

1

28

\section{U.S. Department of Energy, Richland Operations}

J.K. Erickson (20)

A5-19

Public Reading Room

A1-65

Pacific Northwest Laboratory

Hanford Technical Library

P8-55

Bechtel Hanford. Inc.

D.J. Vaught (12)

EPIC (7)

H4-79

ERC (G. Fitzgibbon)

H6-08

ERE (L. Hermann) (2)

H6-07

ERE Project File

H6-07

ER Program Office

H6-08

Resource Center

H6-27

Doc Distribution (S. Hein) (3)

N3-05

H4-79 